Central Washington University

ScholarWorks@CWU

All Faculty Scholarship for the College of the Sciences

College of the Sciences

$11-6-2014$

\title{
A Methodology for Near-Field Tsunami Inundation Forecasting: Application to the 2011 Tohoku Tsunami
}

\author{
Aditya Riadi Gusman \\ Hokkaido University \\ Yuichiro Tanioka \\ Hokkaido University \\ Breanyn Maclnnes \\ Central Washington University, macinnes@geology.cwu.edu \\ Hiroaki Tsushima \\ Japan Meteorological Agency
}

Follow this and additional works at: https://digitalcommons.cwu.edu/cotsfac

Part of the Environmental Monitoring Commons, and the Oceanography and Atmospheric Sciences and Meteorology Commons

\section{Recommended Citation}

Gusman, A. R., Tanioka, Y., Maclnnes, B.T. \& Tsushima, H. (2014). A methodology for near-field tsunami inundation forecasting: Application to the 2011 Tohoku tsunami. Journal of Geophysical Research: Solid Earth, 119(11), 8186-8206. DOI: 10.1002/2014JB010958

This Article is brought to you for free and open access by the College of the Sciences at ScholarWorks@CWU. It has been accepted for inclusion in All Faculty Scholarship for the College of the Sciences by an authorized administrator of ScholarWorks@CWU. For more information, please contact scholarworks@cwu.edu. 


\section{Journal of Geophysical Research: Solid Earth}

\section{RESEARCH ARTICLE \\ 10.1002/2014JB010958 \\ Key Points: \\ A methodology for near-field tsunami inundation forecasting: Application to the $\mathbf{2 0 1 1}$ Tohoku tsunami}

- Development of a new methodology for near-field tsunami inundation forecasting

- Tsunami inundation obtained by the methodology can be similar to the observation

- The new algorithm is remarkably faster than numerical forward modeling

Supporting Information:

- Readme

- Table S1

- Table S2

- Figure S1

- Figure S2

- Figure S3

- Figure S4

- Figure S5

- Figure $S 6$

- Figure S7

- Figure S8

- Figure S9

- Figure S10

- Figure S11

- Figure S12

- Figure S13

- Figure S14

- Figure S15

Correspondence to:

A. R. Gusman,

adit@eri.u-tokyo.ac.jp

Citation:

Gusman, A. R., Y. Tanioka, B. T. Maclnnes, and $\mathrm{H}$. Tsushima (2014), A methodology for near-field tsunami inundation forecasting: Application to the 2011 Tohoku tsunami, J. Geophys. Res. Solid Earth, 119, doi:10.1002/2014JB010958.

Received 15 JAN 2014 Accepted 2 OCT 2014 Accepted article online 7 OCT 2014

\section{Introduction}

\author{
Aditya Riadi Gusman ${ }^{1}$, Yuichiro Tanioka ${ }^{1}$, Breanyn T. Maclnnes², and Hiroaki Tsushima ${ }^{3}$ \\ ${ }^{1}$ Institute of Seismology and Volcanology, Hokkaido University, Sapporo, Japan, ${ }^{2}$ Department of Geological Sciences, \\ Central Washington University, Ellensburg, Washington, USA, ${ }^{3}$ Meteorological Research Institute, Japan Meteorological \\ Agency, Tsukuba, Japan
}

Abstract Existing tsunami early warning systems in the world can give either one or a combination of estimated tsunami arrival times, heights, or qualitative tsunami forecasts before the tsunami hits near-field coastlines. A future tsunami early warning system should be able to provide a reliable near-field tsunami inundation forecast on high-resolution topography within a short time period. Here we describe a new methodology for near-field tsunami inundation forecasting. In this method, a precomputed tsunami inundation and precomputed tsunami waveform database is required. After information about a tsunami source is estimated, tsunami waveforms at nearshore points can be simulated in real time. A scenario that gives the most similar tsunami waveforms is selected as the site-specific best scenario and the tsunami inundation from that scenario is selected as the tsunami inundation forecast. To test the algorithm, tsunami inundation along the Sanriku Coast is forecasted by using source models for the 2011 Tohoku earthquake estimated from GPS, W phase, or offshore tsunami waveform data. The forecasting algorithm is capable of providing a tsunami inundation forecast that is similar to that obtained by numerical forward modeling but with remarkably smaller CPU time. The time required to forecast tsunami inundation in coastal sites from the Sendai Plain to Miyako City is approximately $3 \mathrm{~min}$ after information about the tsunami source is obtained. We found that the tsunami inundation forecasts from the $5 \mathrm{~min}$ GPS, $5 \mathrm{~min}$ W phase, 10 min W phase fault models, and 35 min tsunami source model are all reliable for tsunami early warning purposes and quantitatively match the observations well, although the latter model gives tsunami forecasts with highest overall accuracy. The required times to obtain tsunami forecast from the above four models are $8 \mathrm{~min}, 9 \mathrm{~min}, 14 \mathrm{~min}$, and $39 \mathrm{~min}$ after the earthquake, respectively, or in other words $3 \mathrm{~min}$ after receiving the source model. This method can be useful in developing future tsunami forecasting systems with a capability of providing tsunami inundation forecasts for locations near the tsunami source area.

During the 11 March 2011 Tohoku tsunami, at 3 min after the earthquake, the Japan Meteorological Agency (JMA) issued three types of messages for coastal areas in Japan: tsunami advisory, tsunami warning, and major tsunami warning. These advisory and warning messages were visualized as color-coded lines along the Japanese coastlines on a small-scale map and broadcast on television. Tsunami heights were also forecasted for every region along the Pacific coast of Japan. However, the actual tsunami inundated up to several kilometers inland; for example, the inundation limit in the Sendai Plain was up to $5 \mathrm{~km}$. Although proven to be very useful for the evacuation efforts, qualitative tsunami warnings and forecasted tsunami heights could not illustrate the vast tsunami inundation area. We argue that an accurate tsunami inundation forecast on high-resolution topography could better illustrate the impending tsunami dangers.

The JMA's tsunami early warnings are based on a rapid analysis of seismic waves and a linear interpolation scheme of a precomputed tsunami database from a large set of earthquake scenarios [Tatehata, 1997; Kamigaichi, 2011]. The 2011 Tohoku earthquake's magnitude of Mjma 7.9 was estimated by JMA from strong motion data and was then used to generate the first tsunami warning [Ozaki, 2011]. The initial tsunami height forecast of 3-6 $\mathrm{m}$ for near-field regions was updated several times after considering the observed tsunami at offshore and coastal tide gauge stations. This initial tsunami warning underestimated the real tsunami threat; measured tsunami heights larger than $10 \mathrm{~m}$ were distributed along $500 \mathrm{~km}$ of the Sanriku Coast and reached $40 \mathrm{~m}$ in some places [Mori et al., 2012]. At $28 \mathrm{~min}$ and $44 \mathrm{~min}$ after 
the earthquake, the tsunami height forecast was updated to $6-10 \mathrm{~m}$ and to more than $10 \mathrm{~m}$, respectively [Ozaki, 2011].

To produce a reliable map of tsunami inundation forecast during the event, accurate information of tsunami source is required as soon as possible. The slip distribution of the 2011 Tohoku earthquake (Mw 9.0-9.1) has been estimated by previous studies using teleseismic waves [Ide et al., 2011], strong motion data [Yoshida et al., 2011], GPS data [Ozawa et al., 2011], tsunami waveform data [Fujii et al., 2011; Satake et al., 2013a], or combination of these data [Simons et al., 2011; Yokota et al., 2011; Gusman et al., 2012; Romano et al., 2012; Yue and Lay, 2013]. These detailed models could not be obtained immediately after the earthquake because several inversion parameters can only be set after a seismologist has analyzed the data. Therefore, these types of models are not suitable for tsunami early warning.

Earthquake fault models or tsunami source model for the 2011 Tohoku event that are reliable and robust for tsunami warning purposes could be estimated from GPS data [Ohta et al., 2012], W phase data [Kanamori, 1993; Kanamori and Rivera, 2008; Duputel et al., 2011; Benavente and Cummins, 2013; Gusman and Tanioka, 2013], or offshore tsunami waveform data [Tsushima et al., 2011; Wei et al., 2013]. Ohta et al. [2012] developed a method to estimate static ground displacements in real time due to earthquake faulting from real-time kinematic GPS (RTK-GPS) time series. A fault model with Mw 8.7 for the 2011 Tohoku earthquake was estimated from GPS data that were recorded within $5 \mathrm{~min}$ after the earthquake by GEONET, the GPS continuous observation system operated by the Geospatial Information Authority (GSI) of Japan [Ohta et al., 2012]. Reliable moment magnitude and source parameters of the 2011 Tohoku earthquake can be estimated by using 5 or $10 \mathrm{~min}$ of $\mathrm{W}$ phase data that were recorded by the Japanese F-net stations [Gusman and Tanioka, 2013]. The fault models from the $5 \mathrm{~min} \mathrm{~W}$ phase solutions ( $M w$ 9.0) and the $10 \mathrm{~min}$ W phase solution (Mw 9.1) can give tsunami inundations that match the observations well [Gusman and Tanioka, 2013]. Tsushima et al. [2011] show that reliable tsunami source models can be estimated using tsunami waveforms at offshore stations in the near field that were recorded within 20 and $35 \mathrm{~min}$ after the earthquake.

At least two methods that make use of offshore tsunami data have been developed for real-time tsunami forecasting. The tsunami Forecasting based on Inversion for initial sea Surface Height (tFISH) is a method for near-field tsunami forecasting [Tsushima et al., 2009]. The tFISH algorithm determines an initial sea surface deformation in a possible tsunami source area and then synthesizes coastal tsunami waveforms from the estimated initial sea surface deformation and precomputed tsunami Green's functions [Tsushima et al., 2009, 2011]. The algorithm is currently being integrated into the JMA tsunami forecasting system. The Center for Tsunami Research (NOAA) has developed short-term inundation forecast for tsunamis, a real-time tsunami inundation forecasting scheme [Titov et al., 2005; Tang et al., 2009; Titov, 2009], which is now fully operational in NOAA's Tsunami Warning Center (V. Titov, personal communication, 2013). To ensure early detection of tsunamis, NOAA has deployed Deep-ocean Assessment and Reporting of Tsunami (DART) in regions with a history of generating destructive tsunamis (http://www.ndbc.noaa.gov). The NOAA tsunami forecasting system gives a real-time inversion of the tsunami source by forcing a combination of precomputed unit tsunami propagations to fit the DART measurements through an inversion process and also provides an offshore forecast [Titov et al., 2005; Gica et al., 2008; Wei et al., 2013]. This offshore forecast is then used as input for realtime high-resolution tsunami inundation modeling [Titov et al., 2005; Tang et al., 2009].

Here we introduce a novel methodology for Near-field Tsunami Inundation Forecasting (hereafter, NearTIF). To evaluate the validity of NearTIF method, we perform a retrospective forecast test for the 2011 Tohoku tsunami along the Sanriku Coast from the Sendai Plain to Miyako City, Japan. The NearTIF algorithm requires information about the tsunami source as an input. The fault model inferred from RTK-GPS data [Ohta et al., 2012], two fault models based on W phase solutions [Gusman and Tanioka, 2013], and two improved tsunami source models obtained by tFISH [Tsushima et al., 2011] are used in the test. To validate the forecasting method, the forecasted tsunami inundation is compared with tsunami inundation obtained by numerical forward modeling. The tsunami inundation forecast is also compared with the observation [Mori et al., 2012] to evaluate the accuracy of the forecast from each source model.

\section{Method for Near-Field Tsunami Inundation Forecasting}

Hydrodynamic characteristics of tsunamis are influenced by the tsunami waveform and the surrounding topography and bathymetry [Yeh, 2009]. Tsunami height and period in the nearshore is closely related to the 


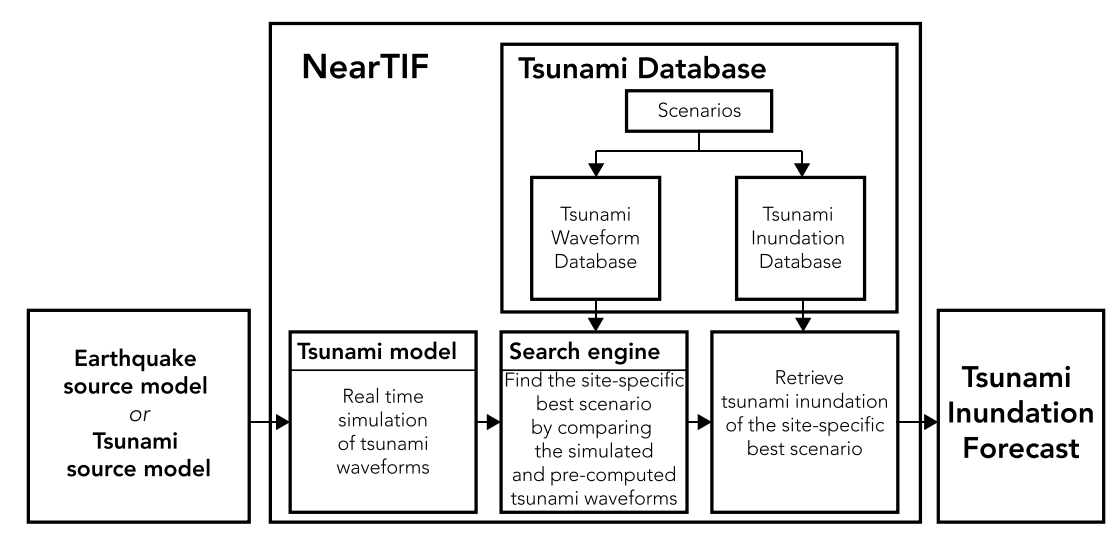

Figure 1. Schematic of the Near-field Tsunami Inundation Forecasting (NearTIF) method.

resulting tsunami inundation on land. In the case of the 2011 Tohoku tsunami, tsunami inundation has been computed by numerical forward modeling from various source models [Satake et al., 2013a; Shimozono et al., 2012; Maclnnes et al., 2013; Wei et al., 2013]. Despite differences of the details in the source models, some of the tsunami inundation results are very similar. If two earthquake models produce similar nearshore tsunami waveforms, then the simulated tsunami inundation from those models are also similar. Based on this reasonable assumption, we develop the method for near-field tsunami inundation forecasting.

We built a database that contains pairs of precomputed tsunami inundation and precomputed tsunami waveforms at specific sites from hypothetical earthquake scenarios. By this method, we will not attempt to obtain a reliable earthquake source model for an event. Instead, any available information about tsunami source such as earthquake's moment magnitude, earthquake fault model, or tsunami source model will be used. Once information about the tsunami source is obtained from seismologists, tsunami waveforms at nearshore points can be simulated in real time. A scenario is selected as the site-specific best scenario by minimizing the root-mean-square (RMS) misfit between the simulated tsunami waveforms and those in the database. Then the corresponding precomputed tsunami inundation of the best scenario is selected as the tsunami inundation forecast. Figure 1 shows the schematic of Near-field Tsunami Inundation Forecasting (NearTIF) method. The details of how we built the tsunami database and how NearTIF selects the site-specific best scenario are explained in the following subsections.

\subsection{Fault Model Scenarios}

The precomputed tsunami database is built from thrust earthquake scenarios of simple rectangular fault models with moment magnitude in the range of $M w 8.0$ to 9.0. We arrange a total of 56 reference points along the subduction zone off the east coast of Honshu, Japan as the center top of the fault planes (Figure 2). The points are grouped into four depth categories of shallowest $(7-11 \mathrm{~km})$, upper intermediate $(12-18 \mathrm{~km})$, lower intermediate $(20-30 \mathrm{~km})$, and deepest $(32-48 \mathrm{~km})$ plate interface. To choose the moment magnitude range of scenarios in each depth category, we follow the model of subduction zone megathrust faults by Lay et al. [2012], where earthquake magnitudes on the deeper part of the plate interface would be smaller than those on the shallower part. The earthquake scenarios for each depth category have moment magnitude range of $M w 8.0$ to 9.0, $M w 8.0$ to 8.9, $M w 8.0$ to 8.8, and $M w 8.0$ to 8.7, respectively, from the shallowest to the deepest plate interface, making a total of 532 scenarios.

Several magnitude-to-area scaling relations to calculate the size of a fault plane have been proposed by previous studies [e.g., Wells and Coppersmith, 1994; Hanks and Bakun, 2002; Blaser et al., 2010]. In this study, we choose the relation by Hanks and Bakun [2002] because it gives a fault size that represents the major slip region of the 2011 Tohoku earthquake [Gusman and Tanioka, 2013]. Length and width of the fault planes are calculated by a simple relationship of length $(L)=2 \times$ width $(W)$. Slip amount of each moment magnitude can be calculated by assuming the rigidity of $4 \times 10^{10} \mathrm{~N} \mathrm{~m}^{-2}$. Dip angle and depth of each scenario are based on the slab model for subduction zone of SLAB1.0 [Hayes et al., 2012], rake angle of $90^{\circ}$ is used for all scenarios. For strike angle, we use $188^{\circ}$ for points in the first-sixth rows, $199^{\circ}$ for points in the seventh-ninth rows, and $210^{\circ}$ for points in the tenth-fourteenth rows from the north 


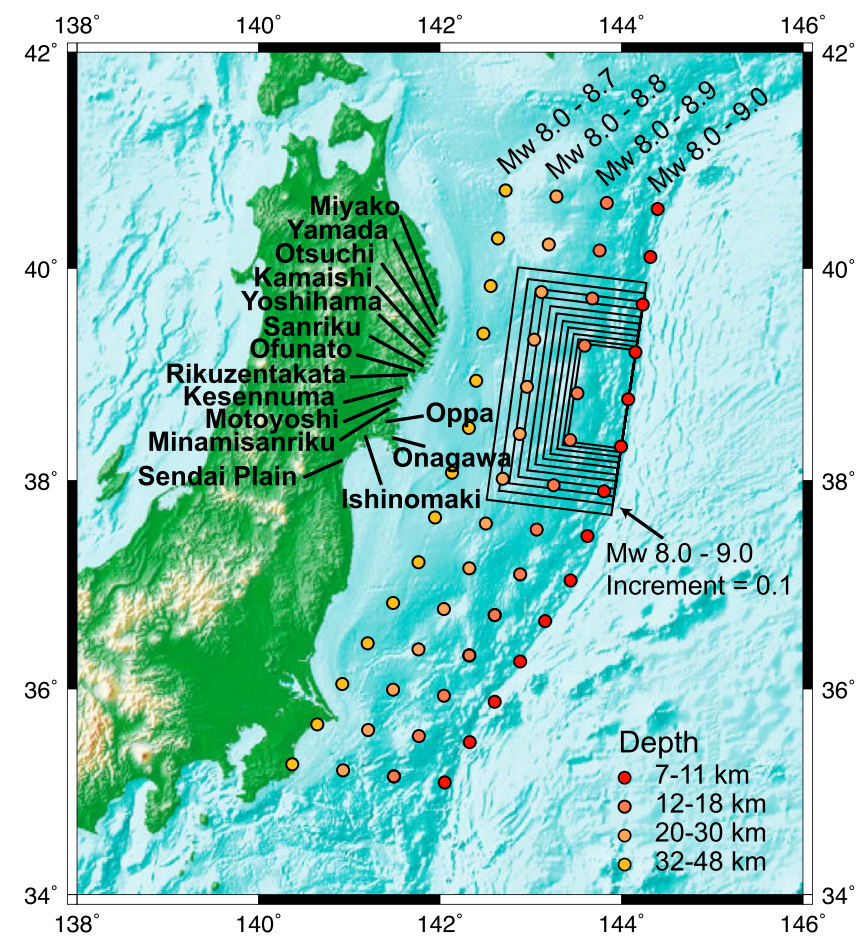

Figure 2. Hypothetical fault models for the precomputed tsunami inundation and precomputed tsunami waveform database. Circles mark the upper center position of the hypothetical fault planes. The forecast sites are indicated.
(Figure 2). The ocean bottom deformation is calculated from the fault model [Okada, 1985], and the sea surface deformation is assumed to be the same as the ocean bottom deformation.

Obviously, the number of scenarios is too limited for a fully developed tsunami inundation forecasting system. Adding more scenarios with different fault parameters and scaling relations could expand the precomputed tsunami database. Nonetheless, the current number of scenarios is enough to show how the NearTIF method works.

\subsection{Site and Virtual Observation Point}

Sites are chosen based on their coastal geomorphology (i.e., bay, lagoon, and isthmus) or the location of a coastal community. Virtual observation points at which tsunami waveforms are computed are placed strategically nearshore, around a bay at depth of deeper than 30 or $50 \mathrm{~m}$ depending on the bathymetry. For sites with wide bays and shallow bathymetry, such as Sendai Bay, the observation points are located at depth as shallow as $30 \mathrm{~m}$ (Figure 3a). For sites with narrow bays such as Rikuzentakata, the observation points are at depth of deeper than $50 \mathrm{~m}$ (Figure 3b). The direction of tsunami propagation is also related to the resulting tsunami inundation on land. To capture information about direction of tsunami propagation, tsunami waveforms at multiple observation points are required. These observation points do not exist nor are required to exist in the real world for the method to work. a)

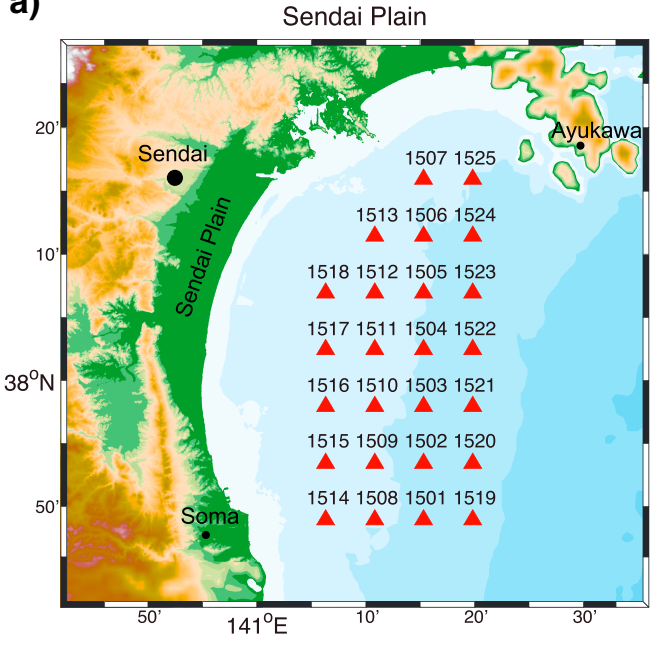

b)

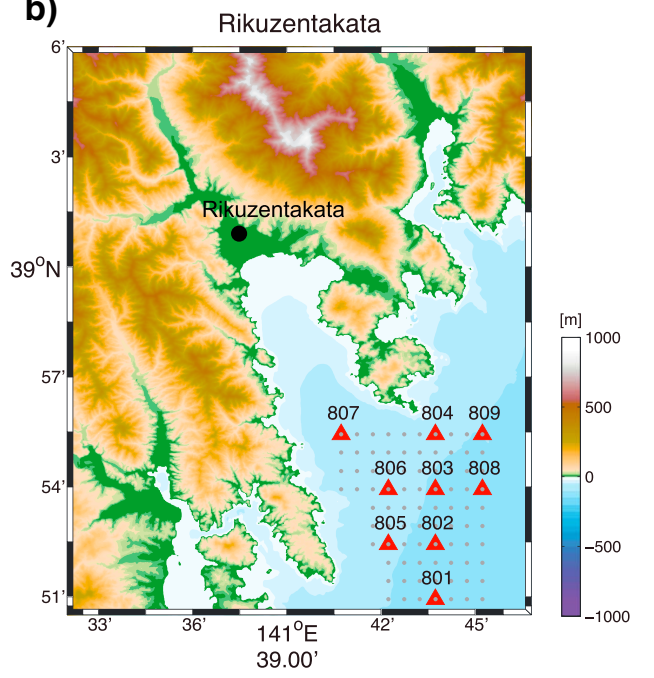

Figure 3. Map of virtual observation points (red triangles) for (a) Sendai Plain and (b) Rikuzentakata. Gray dots are 85 virtual observation points offshore of Rikuzentakata used for the NearTIF's performance test. 
The location and number of virtual observation points are selected to optimize the performance of NearTIF. The performance is characterized by the accuracy and computation time of NearTIF to forecast the tsunami inundation. We test the ability of NearTIF to forecast the tsunami inundation by using tsunami waveforms at random combinations of observation points.

Sendai Bay is approximately $70 \mathrm{~km}$ wide, stretching from Soma in the south to Ayukawa in the north (Figure 3a). The direction of tsunami propagation inside the bay from sources in front, north, and south of the bay is significantly different. In the case of the 2011 Tohoku earthquake, the generated tsunami propagates in the direction normal to the Sendai Plain's coastline. We set a distribution of 25 virtual observation points inside the bay. The best scenario obtained by these observation points is used as reference to find the optimal number of virtual observation points. We found that one observation point in the middle or at either edge of the bay may give an unreliable result. A distribution of 5 to 7 observation points parallel to the coastline gives the same result as when using the 25 observation points.

Rikuzentakata Bay is approximately $15 \mathrm{~km}$ long and between $3 \mathrm{~km}$ and $6 \mathrm{~km}$ wide (Figure $3 \mathrm{~b}$ ). A dense grid of 85 observation points (Figure $3 \mathrm{~b}$ ) can give a tsunami inundation forecast that resembles the tsunami inundation from forward modeling very well. The distance between the observation points along latitude or longitude is $30 \mathrm{arc} \mathrm{sec.} \mathrm{A} \mathrm{shorter} \mathrm{runtime} \mathrm{to} \mathrm{get} \mathrm{the} \mathrm{same} \mathrm{best} \mathrm{scenario} \mathrm{may} \mathrm{be} \mathrm{achieved} \mathrm{when} \mathrm{using} \mathrm{fewer}$ observation points. All runs that used only one or a combination of location and number of observation points give the same best scenario as that from 85 observation points. This indicates that for narrow bays like Rikuzentakata, one observation point is enough. Nevertheless, in this study we used an arbitrary nine observation points for Rikuzentakata. Inappropriate selection of virtual observation points may give an invalid tsunami inundation forecast. Therefore, careful selection of the virtual observation point should be done. The list of carefully selected 161 virtual observation points for all sites that are used in this study can be seen in Table $\mathrm{S} 1$ in the supporting information.

\subsection{Precomputed Tsunami Database}

The tsunami waveforms at the virtual observation points are used in a process of selecting the best scenario. The tsunami waveforms are numerically computed by solving the linear shallow water wave equations using a finite difference scheme. The spherical coordinate system with the origin at the Earth's center is used. The numerical method to compute tsunami propagation is described in Johnson [1998]. The tsunami waveforms from the scenarios at the observation points are simulated over $3 \mathrm{~h}$. We used bathymetry grid with a 30 arc sec resolution. The precomputed tsunami waveforms with $15 \mathrm{~s}$ of time interval are stored in the database.

We simulated tsunami inundation at every site from the earthquake scenarios by solving the nonlinear shallow water wave equations [Imamura, 1996; Johnson, 1998; Goto et al., 1997]. Nested grids of 30, 10, 3.33 , and 1.11 arc sec resolution are used. The tsunami is simulated in the spherical coordinate system. Homogeneous Manning's roughness coefficient of 0.025 is assumed on the grid system, a value widely used in tsunami inundation modeling [Imamura, 2009]. A relationship proposed by Masamura et al. [2000] indicates that bottom surface with Manning's roughness coefficient of 0.025 would be covered by material with a grain diameter of $20 \mathrm{~mm}$ (gravel). Maximum tsunami inundations over $3 \mathrm{~h}$ are stored in the database.

\subsection{Searching the Best Scenario}

Once the tsunami source information is available, tsunami waveforms at the virtual observation points can be simulated by solving the linear shallow-water wave equations using a finite difference scheme. A scenario in the database that gives most similar tsunami waveforms with those from the source model can be found by RMS (root-mean-square) misfit/error analysis. To speed up the process, the NearTIF algorithm analyzed only sets of tsunami waveforms with the mean of maximum heights that is within a threshold of $30 \%$ from the reference. A time window based on two cycles of tsunami waveform is used for the RMS analysis. The wave cycles of a tsunami waveform can be automatically detected by the zero up/down crossing method. Direct comparison between the precomputed tsunami waveforms in the database and those from numerical forward modeling makes most of the scenarios give bad misfits because of the wave phase differences. To solve this problem, the tsunami waveforms are shifted by an optimal time shift ( $\tau$ o) that minimizes the RMS misfit of the waveforms (Figure 4). By this process, every scenario will have an RMSE (root-mean-square error) value for the set of tsunami waveforms. Then, a scenario that gives the smallest RMSE value is selected as the site-specific best scenario. 
a)

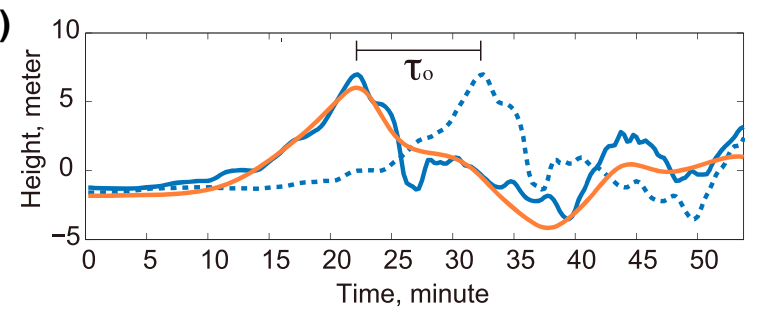

b)

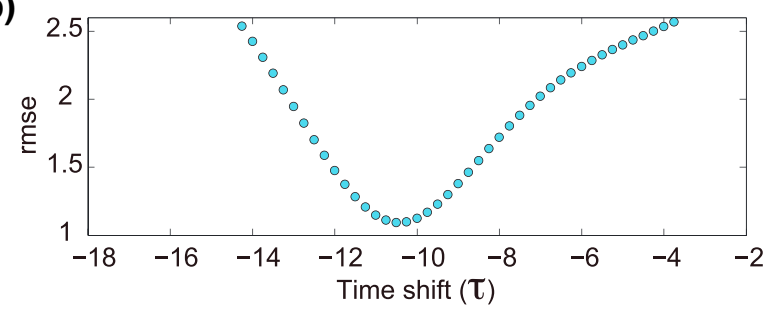

Figure 4. (a) Simulated tsunami waveform (blue dashed line), simulated tsunami waveform that is shifted by the optimal time shift $\left(\tau_{0}\right)$ (blue line), and tsunami waveform from the best scenario (orange line). (b) Plot of RMSE (root-mean-square error) against the time shift.

\section{Data}

\subsection{Bathymetry and Topography}

The bathymetry and topography near the forecast site (such as local shelf, coastline shape, harbor geometry, and nearby islands) strongly influence the local tsunami wave characteristics [Tang et al., 2008]. Accurate high-resolution bathymetric and topographic data are crucial for evaluating tsunami dynamics in the coastal environment [Mofjeld et al., 2001; Tang et al., 2008]. The bathymetric data set used for tsunami simulation is based on the General Bathymetric Chart of the Oceans (GEBCO) 30 arc sec grid resolution, Japan Hydrographic Association's M7005 bathymetric contour data, and digital elevation model (topographic data) of Geospatial Information Authority of Japan (GSI) with $50 \mathrm{~m}$ of grid resolution. The combination of bathymetric and topographic data set is resampled to different grid sizes of 30, 10, 3.33, and 1.11 arc sec for the nested grid systems.

\subsection{Tsunami Inundation Data of the 2011 Tohoku Tsunami}

Posttsunami survey along the coast of Japan provided more than 5200 measurements of the 2011 Tohoku tsunami inundation, including tsunami height and runup [Mori et al., 2012]. Maximum tsunami heights greater than $10 \mathrm{~m}$ are distributed along $500 \mathrm{~km}$ of the Sanriku Coast. Extreme tsunami runups up to $40 \mathrm{~m}$ were measured at V-shaped valleys along the Sanriku Coast between $39^{\circ}$ and $40^{\circ} \mathrm{N}$. The inundation limit of the tsunami was mapped in every major town by the Japan Society of Geoinformatics (http://www.jsgi-map. org/tsunami/google_tile_en.html). We use these tsunami inundation data to evaluate the accuracy of tsunami inundation forecast.

\section{Fault Models and Tsunami Source Models}

\subsection{Fault Model of RTK-GPS (Real-Time Automatic Detection Method for Permanent Displacement)}

Real-time Automatic detection method for Permanent Displacement (RAPiD) algorithm was developed to estimate the amount of displacement from RTK-GPS time series Ohta et al. [2012]. Coseismic displacement fields due to the 2011 Tohoku earthquake were estimated by the RAPiD algorithm using $1 \mathrm{~Hz}$ GPS data recorded at 527 GEONET stations. The final fault model and coseismic displacement field due to the earthquake were estimated within $4 \mathrm{~min} 35 \mathrm{~s}$ from the origin time. The fault model estimated from the final coseismic displacement has fault length of $281.5 \mathrm{~km}$, fault width of $127.4 \mathrm{~km}$, strike of $194.3^{\circ}$, dip of $17.3^{\circ}$, rake of $73.5^{\circ}$, and slip amount of $15.2 \mathrm{~m}$ (Mw 8.7) [Ohta et al., 2012]. The sea surface deformation from the fault model is shown in Figure 5. The estimated moment magnitude of $M w 8.7$ is much closer to Mw 9.0 [Ozawa et al., 2011] than the final solution (M 8.1) of the JMA's Earthquake Early Warning system [Ohta et al., 2012].

\subsection{Fault Models of W Phase Solutions}

Centroid moment tensor solutions for the 2011 Tohoku earthquake were estimated using $5 \mathrm{~min}$ and $10 \mathrm{~min}$ of W phase data recorded at the Japan F-net stations. Fault models from the $5 \mathrm{~min} \mathrm{~W}$ phase solution (length $=246 \mathrm{~km}$, width $=123 \mathrm{~km}$, strike $=221^{\circ}$, dip $=24^{\circ}$, rake $=137^{\circ}$, and slip amount $=31 \mathrm{~m}$ ) and $10 \mathrm{~min} \mathrm{~W}$ phase solution (length $=268 \mathrm{~km}$, width $=134 \mathrm{~km}$, strike $=207^{\circ}$, dip $=17^{\circ}$, rake $=89^{\circ}$, and slip amount $=37 \mathrm{~m}$ ) are obtained by Gusman and Tanioka [2013]. The sea surface deformations from the fault models are shown in Figure 5.

\subsection{Initial Sea Surface Solutions of tFISH}

Tsunami waveforms recorded at nine offshore stations, including two tsunami meters (TM), 2 Kushiro-Oki pressure gauges, and 5 GPS buoys, were inverted by the tFISH algorithm to obtain the initial sea surface 

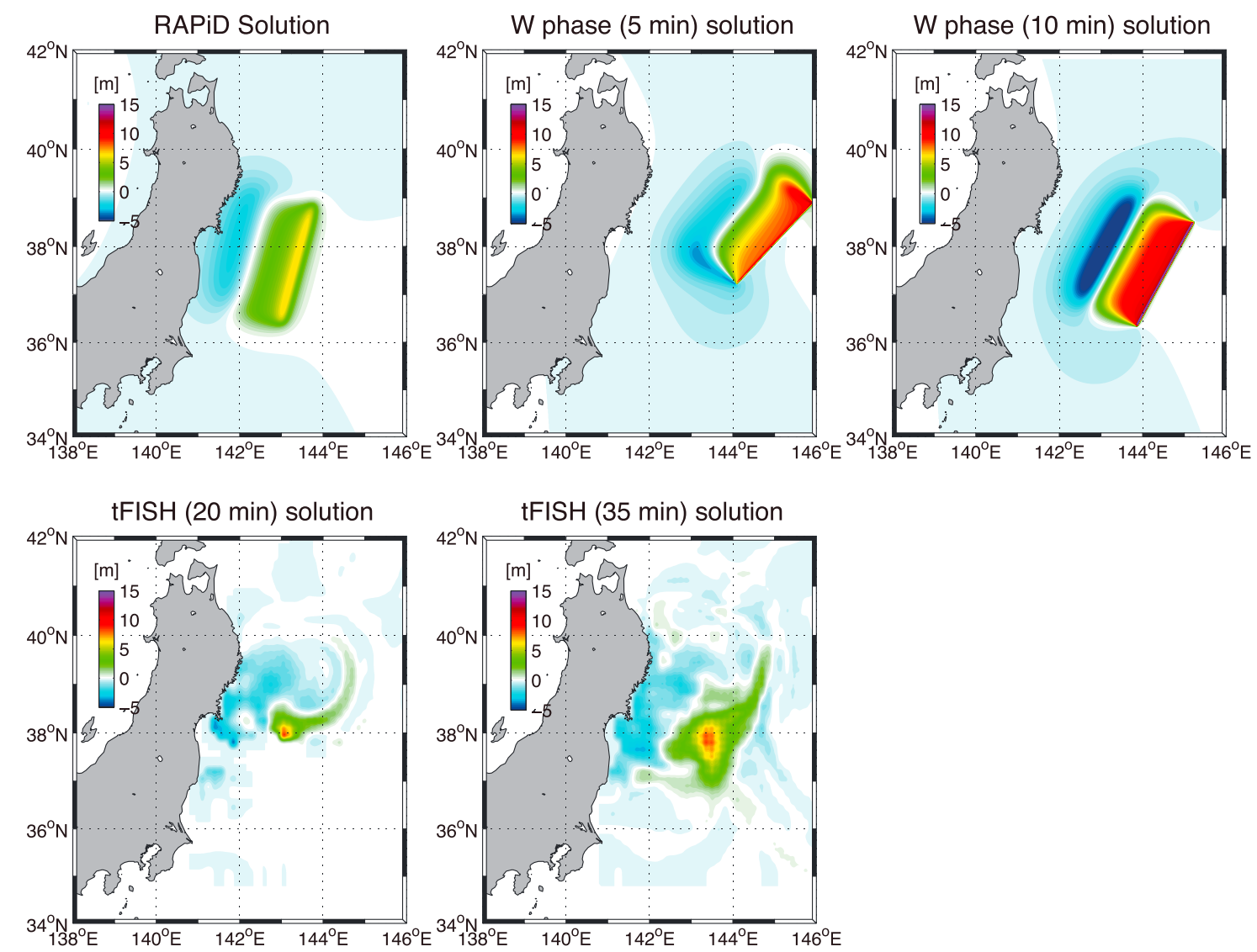

Figure 5. Initial sea surface deformations from the RAPiD, $5 \mathrm{~min} \mathrm{~W}$ phase, $10 \mathrm{~min} \mathrm{~W}$ phase, tFISH $20 \mathrm{~min}$, and tFISH 35 min solutions.

deformation for the 2011 Tohoku tsunami [Tsushima et al., 2011]. Reliable initial sea surface deformations can be estimated by using tsunami waveforms that were recorded within $20 \mathrm{~min}$ and $35 \mathrm{~min}$ after the earthquake [Tsushima et al., 2011]. We improved the solutions by using four additional tsunami waveforms recorded at other offshore stations (one GPS buoy, two BOSO pressure gauges located off the Boso peninsula, and one DART), and the waveforms at the initial five GPS buoys that were not available during the event. We also improved the smoothness of initial sea surface deformation by replacing the unit source that has a stair-like slope [Tsushima et al., 2009, 2011] with a two-dimensional Gaussian. The improved initial sea surface deformations of tFISH 20 min solution and tFISH 35 min solution are shown in Figure 5 . The settings to compute the tsunami Green's functions for the tFISH are explained in Tsushima et al. [2009, 2011].

\section{Tsunami Inundation Result}

To validate the forecasting method, the forecasted tsunami inundation is compared with tsunami inundation from numerical forward modeling and with observations. Aida [1978] introduced the parameter $K$ that indicates the relative size of the observed and simulated tsunami heights, and $\kappa$ (kappa) that indicates the precision of the simulated tsunami heights. The Aida number $K$ and $\kappa$ are commonly used to compare observed and simulated tsunami heights [Satake and Tanioka, 2003; Nakamura, 2006; Satake, 2007; Koshimura et al., 2009; Nakamura, 2009; Maclnnes et al., 2013]. To evaluate the accuracy of the forecast, we used the geometric mean ratio of Aida [1978] number $K$ and its corresponding standard deviation $\kappa$ that can be written as

$$
\begin{gathered}
\log K=\frac{1}{N} \sum_{i=1}^{N} \log K_{i} ; K_{i}=\frac{O_{i}}{S_{i}} \\
\log \kappa=\sqrt{\frac{1}{N} \sum_{i=1}^{N}\left(\left(\log K_{i}\right)^{2}-(\log K)^{2}\right)}
\end{gathered}
$$


a) tFISH (35 min) solution

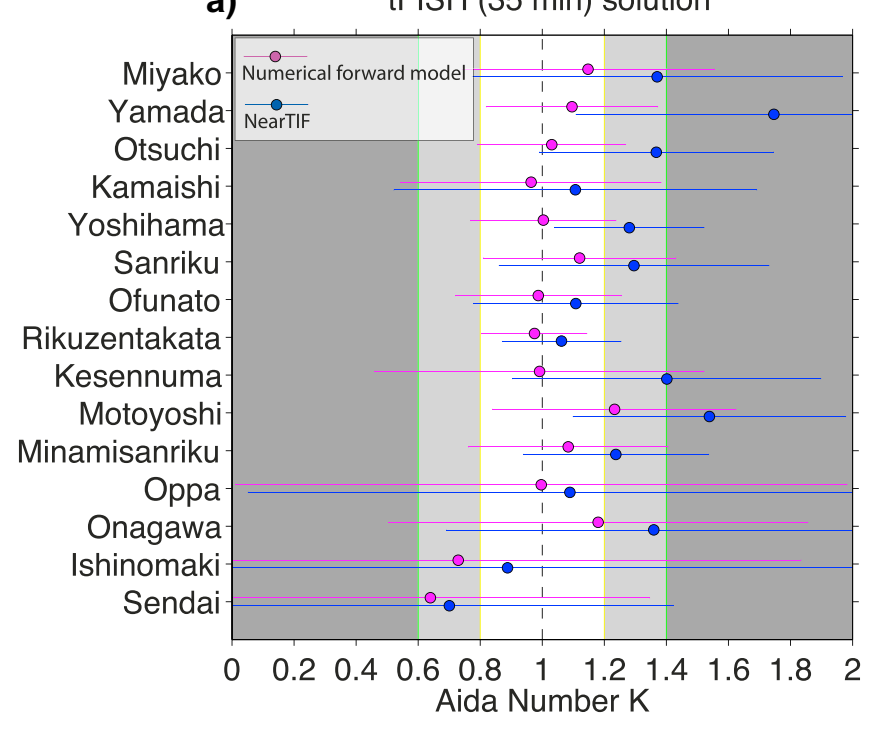

b)

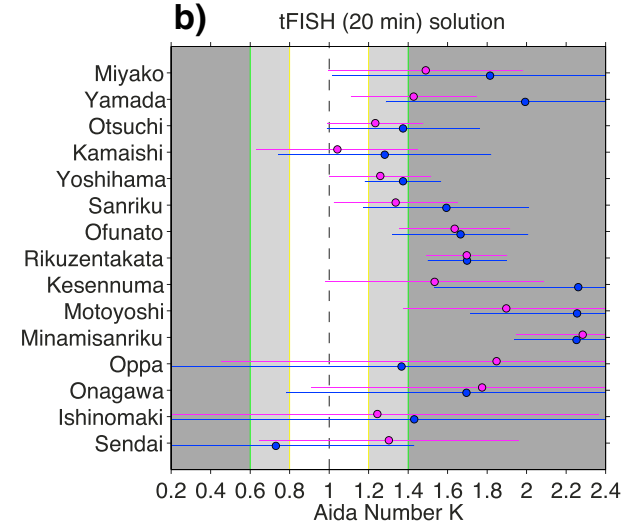

d)

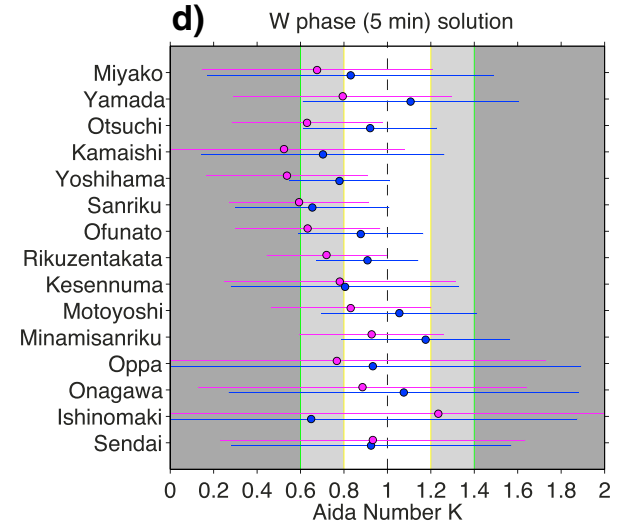

c) RAPiD solution

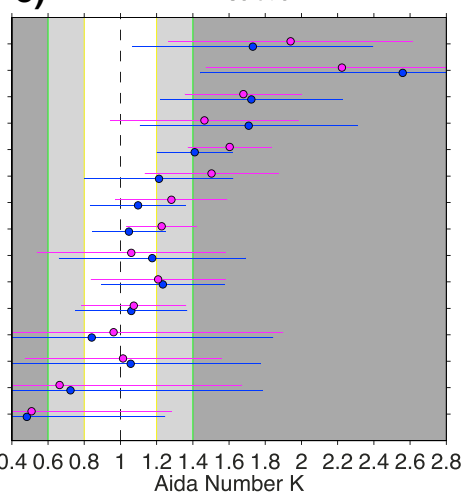

e) $\quad W$ phase $(10 \mathrm{~min})$ solution

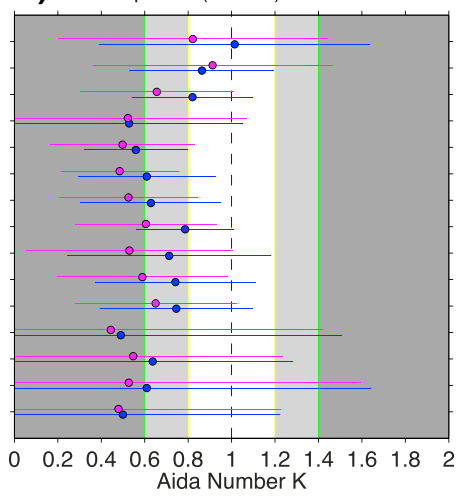

Figure 6. Accuracy of forecasted tsunami inundation from the (a) tFISH ( $35 \mathrm{~min}$ ) solution, (b) tFISH (20 min) solution, (c) RAPiD solution, (d) W phase $(5 \mathrm{~min})$ solution, and (e) W phase $(10 \mathrm{~min})$ solution of the 2011 Tohoku earthquake. $K$ value and its standard deviation $\kappa$ are indicated by circle and bar, respectively. Magenta is for the result by numerical forward modeling and blue is for the result by NearTIF. Light gray areas are for $0.6<K \leq 0.8$ or $1.2 \leq K<1.4$, and dark gray areas are for $K \leq 0.6$ or $K \geq 1.4$.

where $K_{i}$ is the ratio between observed tsunami height $\left(O_{i}\right)$ and simulated tsunami height $\left(S_{i}\right)$. We consider a forecasted tsunami inundation by forward modeling or from the best scenario to have an acceptable accuracy (slightly underestimating or overestimating the observation) when its Aida number $K$ is within a threshold of $1 \pm 0.4$. Tsunami inundation forecasts with Aida number $K$ larger than 1.04 and smaller than 

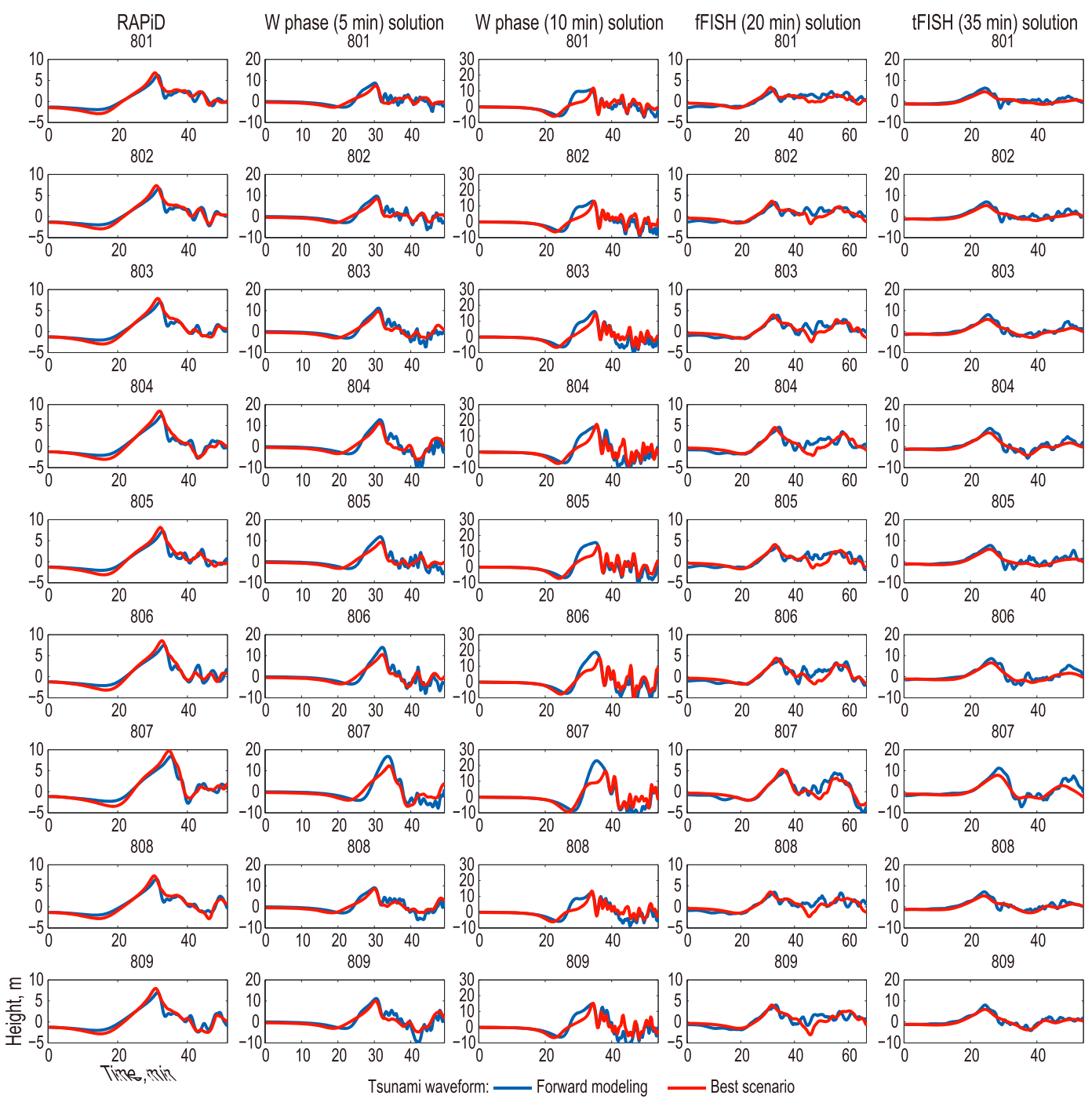

Figure 7. Comparisons between tsunami waveforms by forward modeling (blue lines) and that from the best scenarios (red lines) in Rikuzentakata for the RAPiD, 5 min W phase, 10 min W phase, tFISH 20 min, and tFISH 35 min solutions.

0.6 (dark gray areas in Figure 6), respectively, are considered to strongly underestimate and overestimate the observation. The accuracy of the forecasted tsunami inundation for every solution at every site is shown in Figure 6 and Table S2.

\subsection{Fault Model of RTK-GPS (RAPiD)}

The RAPiD fault model is used to simulate tsunami waveforms at the virtual observation points for every site. The comparisons of the simulated tsunami waveforms in Rikuzentakata from the RAPiD fault model with those from the selected best scenario are shown in Figure 7. The tsunami inundation obtained by forward modeling and that from the best scenario are similar (Figure 8). The tsunami inundation from forward modeling is similar to the actual tsunami heights $(K=1.23)$ and the limit of inundation. The tsunami inundation forecast of the best scenario is very similar to the actual tsunami heights with $K=1.05$ (Figure $8 \mathrm{~b}$ ). The forecasted tsunami inundations in most sites underestimate the observation, and the underestimations are stronger in sites to the north, from Sanriku to Miyako (Figure 6c); this can be explained by the solution's moment magnitude of $M w 8.7$ which is smaller than the moment magnitude of $M w 9.0$ estimated by a previous study that also used GPS data [Ozawa et al., 2011]. 
a)
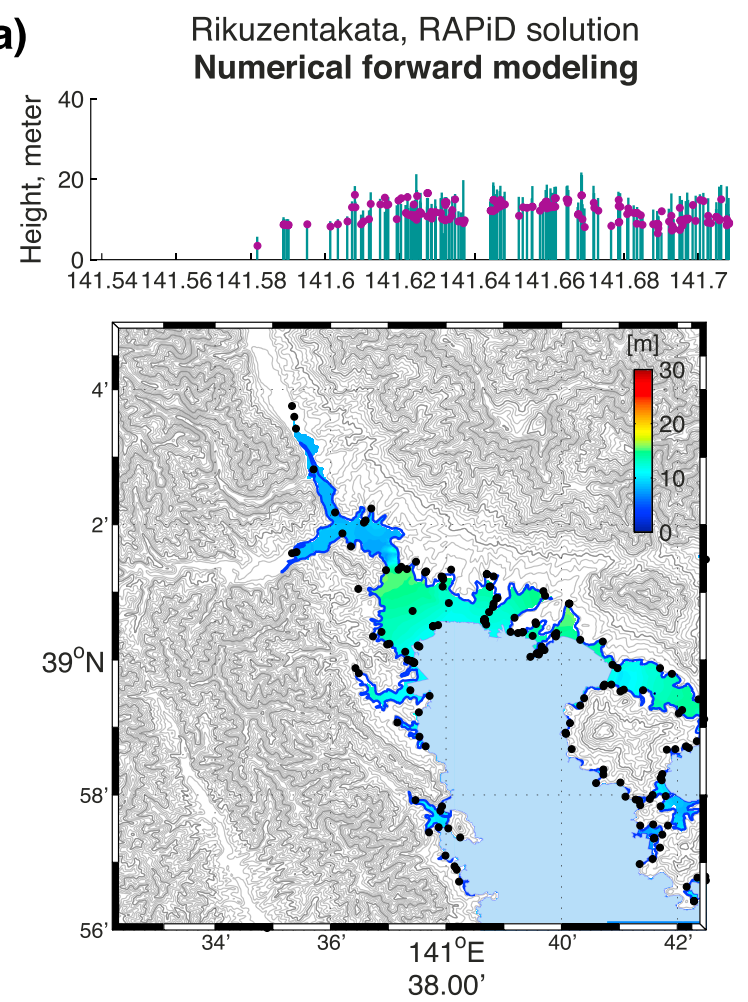

b)
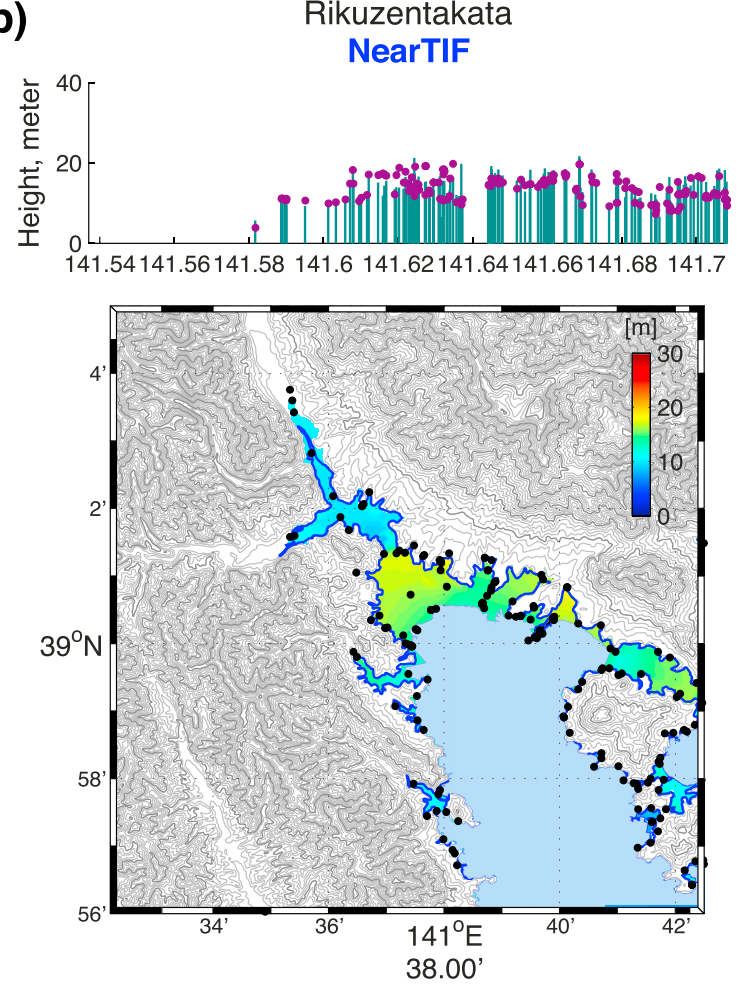

Tsunami Height

$\mathrm{K}=1.23$

$\kappa=1.20$

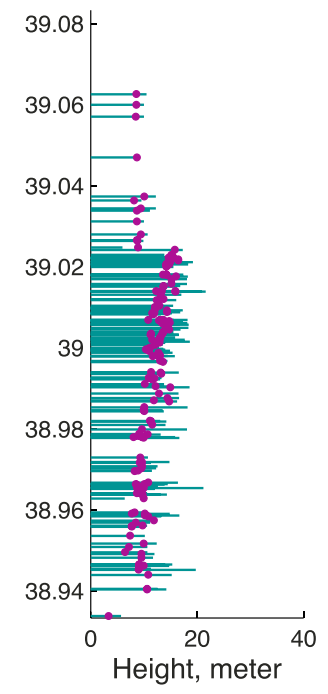

Tsunami Height

$\mathrm{K}=1.05$

$\kappa=1.20$

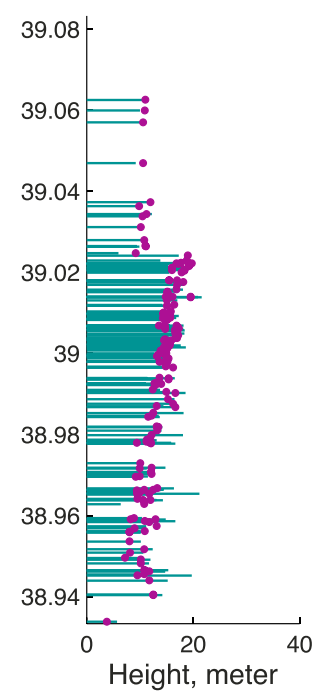

Figure 8. Tsunami inundation forecasts in Rikuzentakata produced by (a) numerical forward modeling and (b) NearTIF from the RAPiD solution. Green bars represent the measured tsunami heights, magenta dots represent the forecasted tsunami heights, blue lines represent the actual limit of inundation, and black dots are the measured positions. 
a)
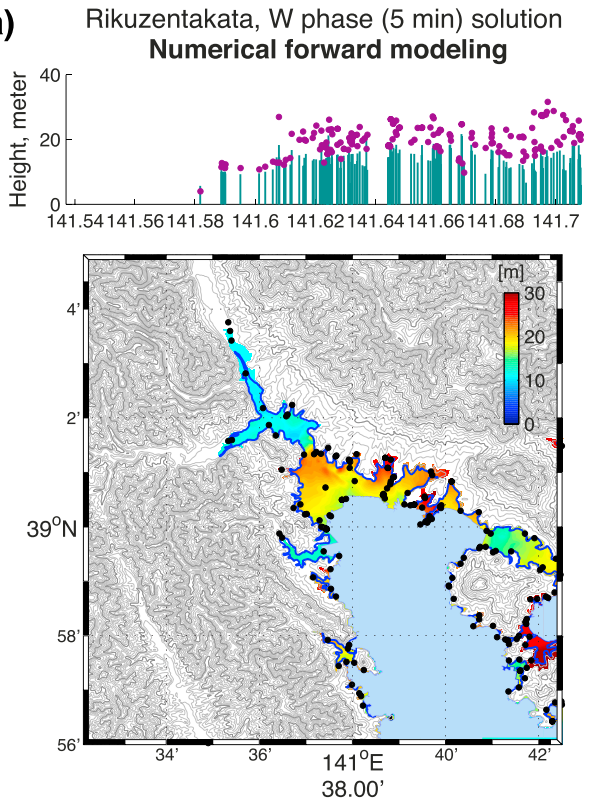

b)
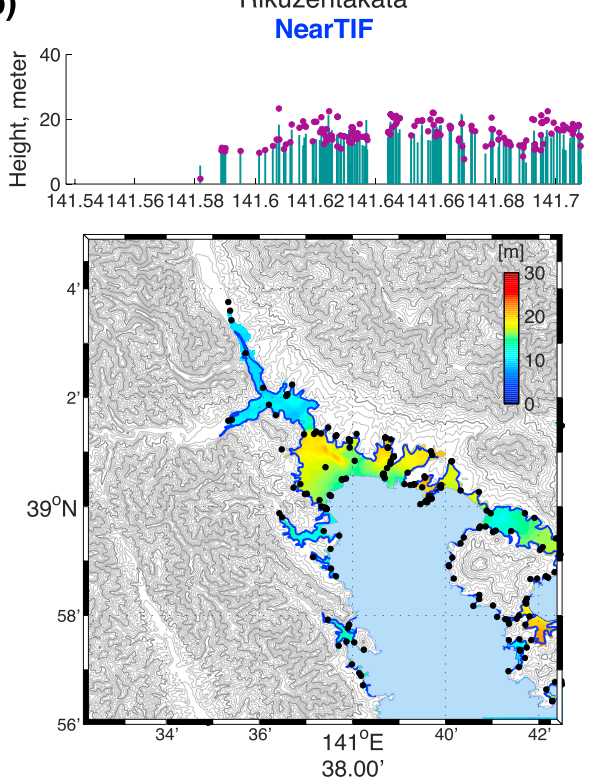

Tsunami Height

$\mathrm{K}=0.72$

$\kappa=1.28$

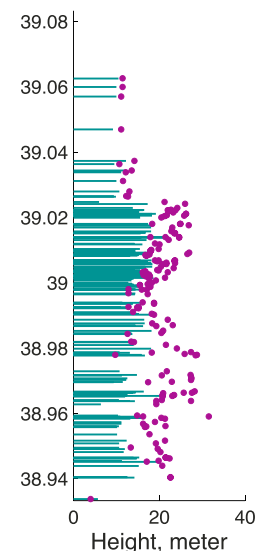

Tsunami Height

$\mathrm{K}=0.91$

$\kappa=1.23$

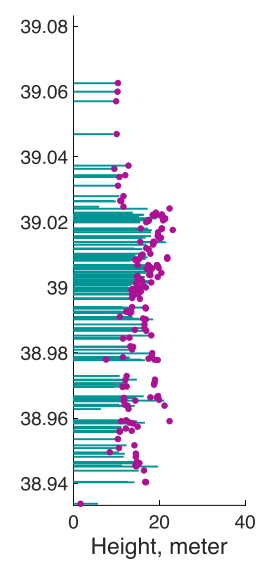

Figure 9. Tsunami inundation forecasts in Rikuzentakata produced by (a) numerical forward modeling and (b) NearTIF from the fault model of $5 \mathrm{~min}$ W phase solution. Green bars represent the measured tsunami heights, magenta dots represent the forecasted tsunami heights, blue lines represent the actual limit of inundation, and black dots are the measured positions.

other solutions (Figure 6), and most of the forecasts produced by NearTIF slightly overestimate the observation (Figure 6e). The source parameters (i.e., strike, dip, and rake) of the $10 \mathrm{~min} \mathrm{~W}$ phase solution are consistent with the WCMT solution by USGS. The estimated magnitude of $10 \mathrm{~min} \mathrm{~W}$ phase solution $(M w 9.1)$ is slightly larger than that estimated by the USGS ( $M w$ 9.0). Thus, the $10 \mathrm{~min}$ W phase solution gives a more conservative forecast of tsunami inundation along the Sanriku Coast.

\subsection{Initial Sea Surface Solutions of tFISH}

The comparisons of the synthesized tsunami waveforms from the tFISH 20 min and 35 min solutions with those from the corresponding scenarios for Rikuzentakata are shown in Figure 6. The tsunami 
a) Rikuzentakata, W phase (10 min) solution
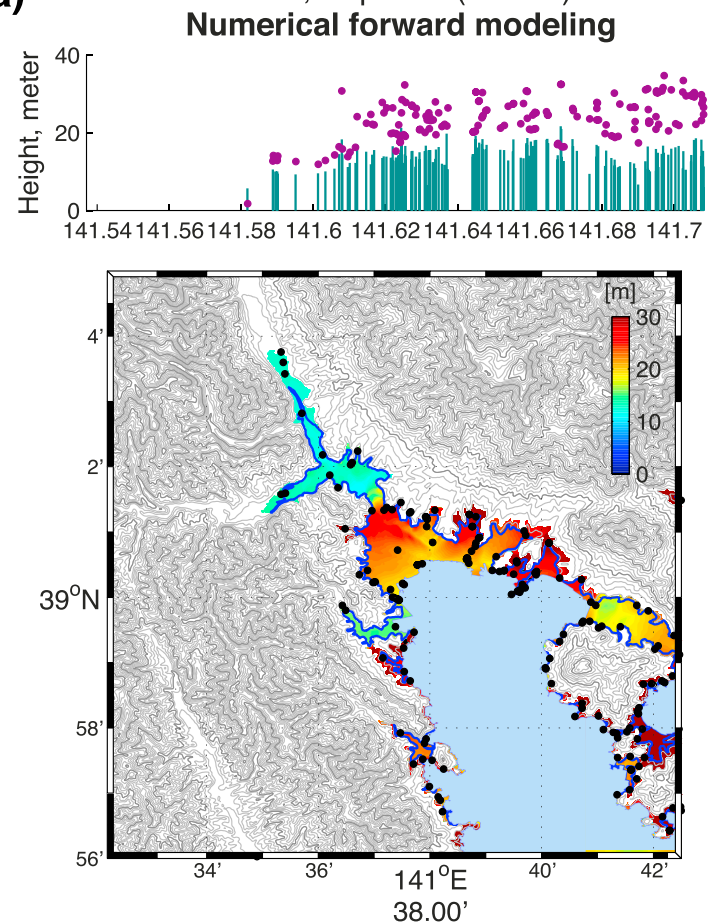

b)
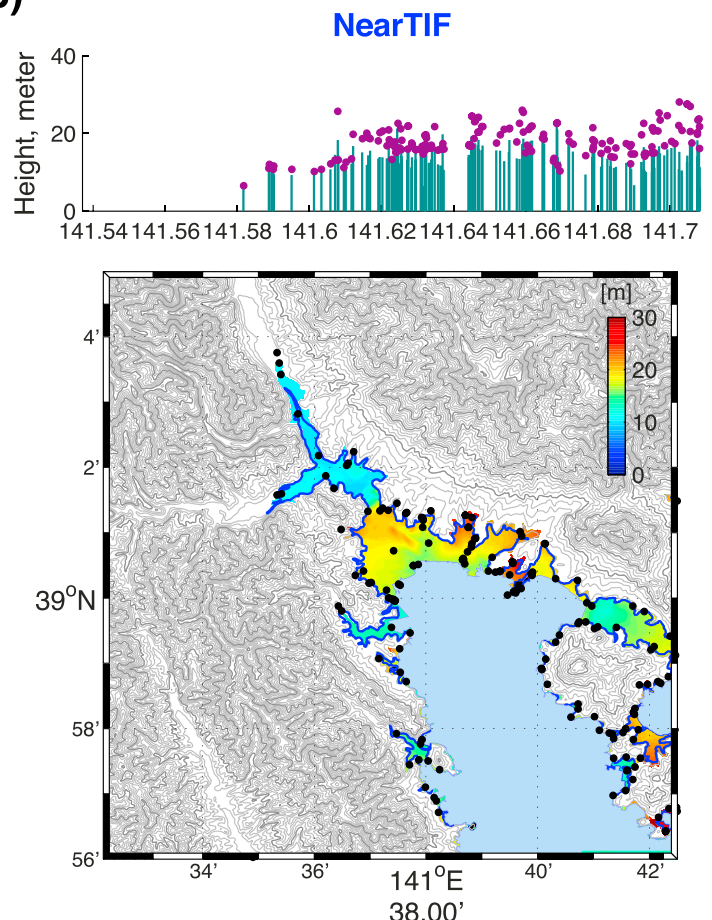

Tsunami Height

$\mathrm{K}=0.61$

$\kappa=1.33$

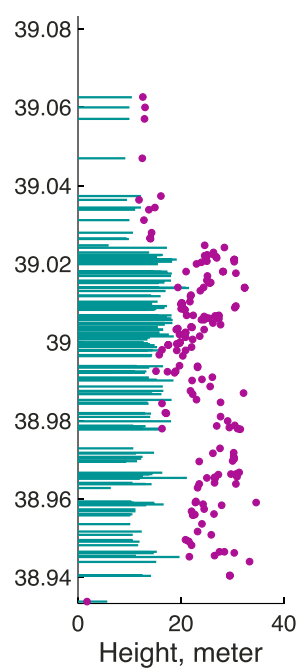

Tsunami Height

$\mathrm{K}=0.79$

$\kappa=1.23$

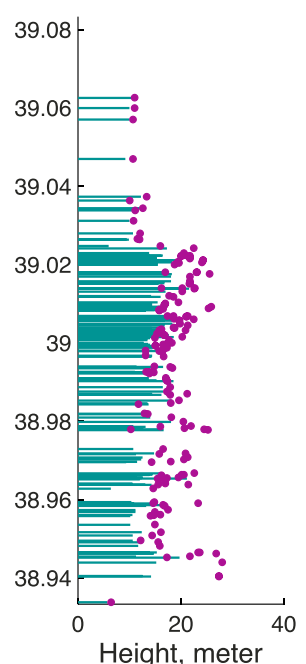

Figure 10. Tsunami inundation forecasts in Rikuzentakata produced by (a) numerical forward modeling and (b) NearTIF from the fault model of $10 \mathrm{~min} \mathrm{~W}$ phase solution. Green bars represent the measured tsunami heights, magenta dots represent the forecasted tsunami heights, blue lines represent the actual limit of inundation, and black dots are the measured positions. 
a)
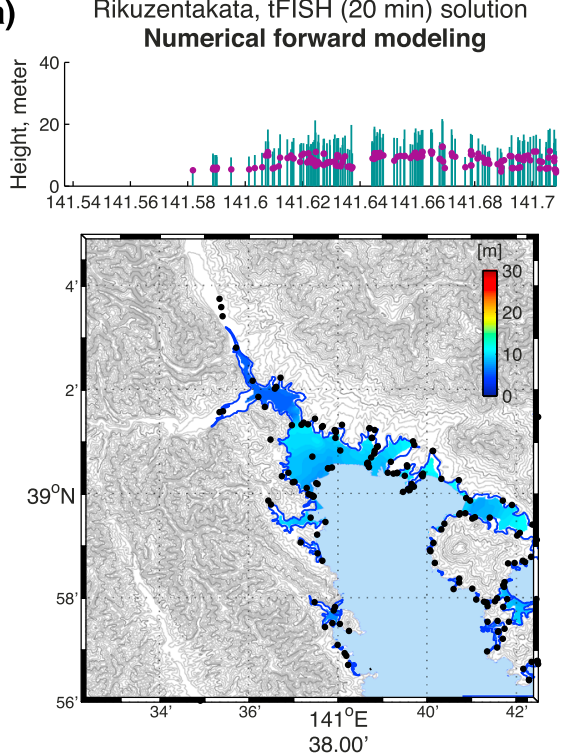

b)
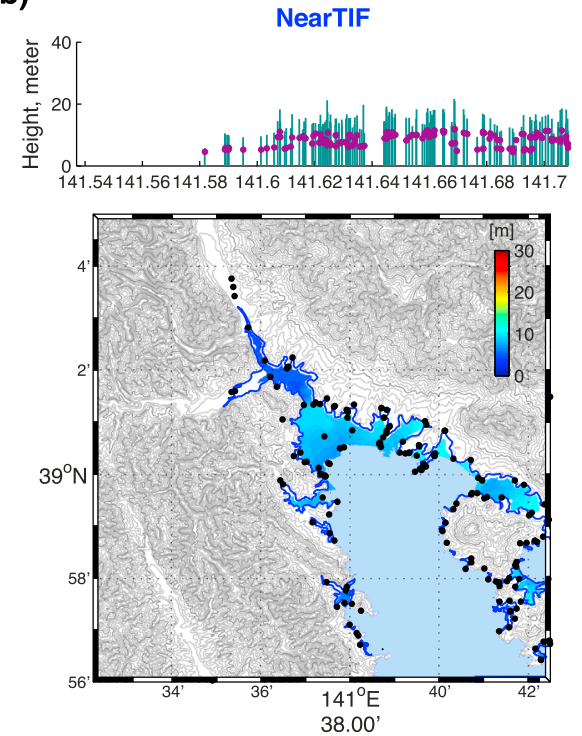

Tsunami Height

$\mathrm{K}=1.70$

$\kappa=1.20$

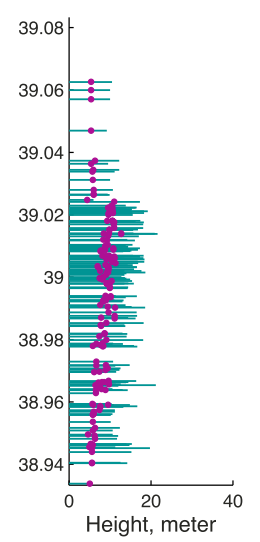

Tsunami Height $\mathrm{K}=1.70$ $\kappa=1.20$

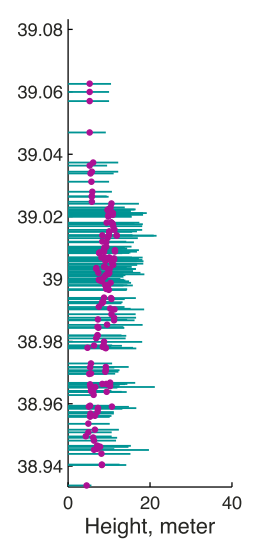

Figure 11. Tsunami inundation forecasts in Rikuzentakata produced by (a) numerical forward modeling and (b) NearTIF from the tFISH 20 min solution. Green bars represent the measured tsunami heights, magenta dots represent the forecasted tsunami heights, blue lines represent the actual limit of inundation, and black dots are the measured positions.

inundation from numerical forward modeling and that from the best scenario for every tFISH solution are similar (Figures 11 and 12).

The tsunami inundation simulated numerically from the tFISH $20 \mathrm{~min}$ solution in Rikuzentakata strongly underestimates the observed tsunami heights $(K=1.70)$ but is close to the observed limit of inundation (Figure 11a). The tsunami inundation forecast obtained by NearTIF for the tFISH 20 min solution also strongly underestimates the observation $(K=1.70)$ (Figure 11b). Our result shows that the tsunami inundations in most sites also strongly underestimate the observation $(K>1.40$ ) (Figure $6 b)$. This may suggest that the $20 \mathrm{~min}$ tsunami waveforms do not contain complete information of the total tsunami source energy.

The forecasted tsunami inundations for the tFISH 35 min solution for all sites from the Sendai Plain to Miyako City are shown in Figures S1-S15. The tsunami inundations simulated by numerical forward modeling from the tFISH 35 min solution in most of the sites (12 out of 15 ) are very accurate with $K$ values within $1 \pm 0.2$ (Figure 6 and Table 1). The NearTIF could produce tsunami inundation forecasts that are comparable with tsunami inundation from the relatively expensive numerical forward modeling. The tsunami inundations produced by NearTIF very closely resemble the tsunami inundations from numerical forward modeling in nine sites (Kamaishi, Sanriku, Ofunato, Rikuzentakata, Minamisanriku, Oppa,

Onagawa, Ishinomaki, and Sendai Plain), moderately resemble the tsunami inundations from numerical forward modeling in four sites (Miyako, Otsuchi, Yoshihama, and Motoyoshi), and poorly resemble the tsunami inundations from numerical forward modeling in two sites (Yamada and Kesennuma). For example, in Rikuzentakata, the tFISH 35 min solution gives tsunami inundation from numerical forward modeling and tsunami inundation produced by NearTIF that are very similar to the observation with $K$ of 0.97 and 1.06, respectively (Figures $12 \mathrm{a}$ and $12 \mathrm{~b}$ ).

The 2011 Tohoku earthquake is a combination of a shallow slip (tsunami earthquake type) and a "typical" great underthrust earthquake [Fujii et al., 2011; Satake et al., 2013a]. A tsunami earthquake is identified as having anomalously slow rupture velocity in the shallowest part of subduction zones [Kanamori, 1972; Newman et al., 2011; Lay et al., 2012]. Satake et al. [2013a] shows that delayed slip near the Japan Trench is required in order to explain the high runups along the northern part of Sanriku Coast. This shallow slip has a 
a) Rikuzentakata, $\mathrm{tFISH}(35 \mathrm{~min})$ solution
$\quad$ Numerical forward modeling
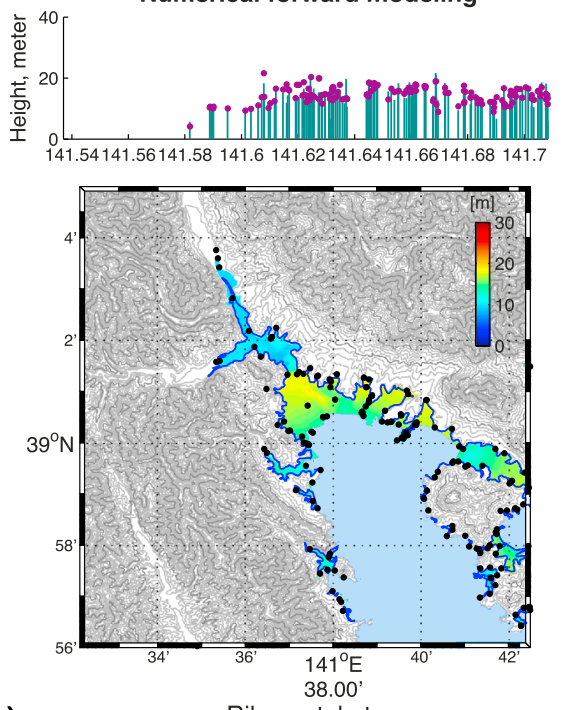

b)
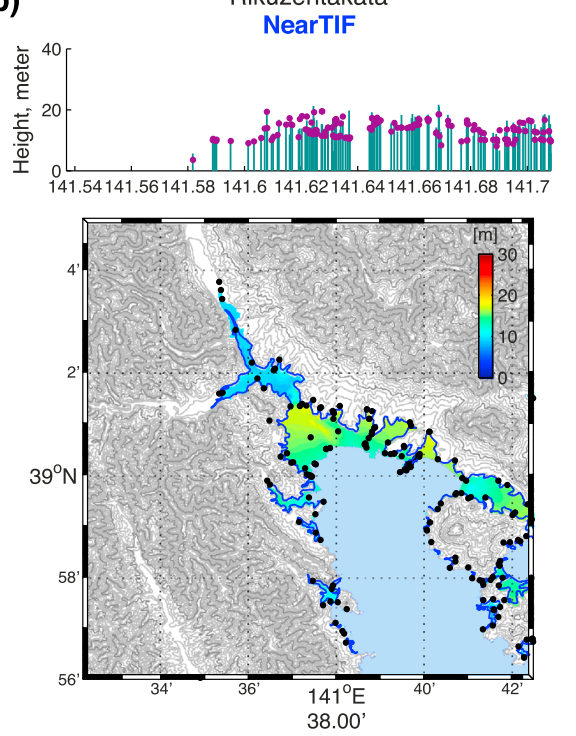

Tsunami Height

$\mathrm{K}=0.97$

$\kappa=1.17$

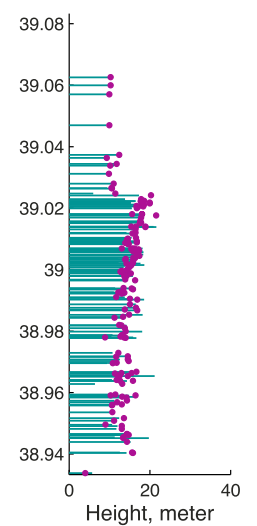

Tsunami Height

$\mathrm{K}=1.06$

$\kappa=1.19$

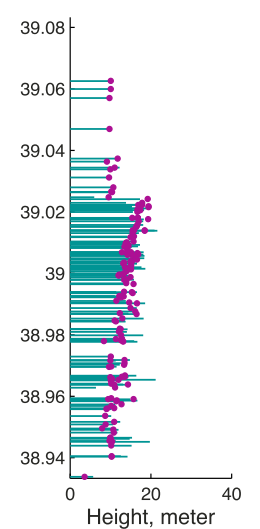

Figure 12. Tsunami inundation forecasts in Rikuzentakata produced by (a) numerical forward modeling and (b) NearTIF from the tFISH $35 \mathrm{~min}$ solution. Green bars represent the measured tsunami heights, magenta dots represent the forecasted tsunami heights, blue lines represent the actual limit of inundation, and black dots are the measured positions.

similar characteristic with the 1896 tsunami earthquake [Tanioka and Satake, 1996] that occurred in the same region. The sea surface deformation pattern of the tFISH 35 min solution is consistent with the previous study and indicates that both types of earthquake rupture may indeed had occurred during the 2011 Tohoku earthquake. The capability of the NearTIF method to forecast the tsunami inundation from the complex event is tested here. It revealed that although the tsunami database is built from simple rectangular fault models, accurate tsunami inundation forecast could still be obtained for most sites.

\section{Computation Speed}

For this study, we used a laptop computer with an Intel ${ }^{\circledR}$ Core i7 processor, running at $2.7 \mathrm{GHz}$, which is supported by $8 \mathrm{~GB}$ of memory. Realtime simulation of tsunami waveforms at the virtual observation points by solving the linear shallow water equations does not take a long time. Simulating $3 \mathrm{~h}$ of tsunami waveforms requires less than $2 \mathrm{~min}$. We used OpenMP (Open Multiprocessing) directives to make our tsunami program run in parallel simultaneously on multiple cores. The process of searching the best scenario by the RMS analysis for a site takes 2 to $10 \mathrm{~s}$, depending on the number of virtual observation points that a site has. In this study, there are 15 sites with 161 observation points from the Sendai Plain to Miyako City. The process to search the site-specific best scenarios

for all sites takes approximately $1 \mathrm{~min}$. In total, the time required by NearTIF to forecast tsunami inundations in the 15 sites is approximately $3 \mathrm{~min}$ after information about the tsunami source is obtained. The speed of the NearTIF algorithm to obtain the tsunami inundation forecast is remarkably (hundreds of times) faster than that by numerical forward modeling. It takes roughly $40 \mathrm{~h}$ to obtain maximum tsunami inundations for all sites by numerical forward modeling on the same grid resolution (Table 2).

After the earthquake occurs, the tsunami inundation forecasts for 15 sites are ready for dissemination within $8 \mathrm{~min}$ ( $5 \mathrm{~min}$ to obtain the final fault model and $3 \mathrm{~min}$ for NearTIF) when using the RAPiD solution, $9 \mathrm{~min}$ when using the $5 \mathrm{~min} \mathrm{~W}$ phase solution ( $5 \mathrm{~min}$ for data, $1 \mathrm{~min}$ for inversion, and $3 \mathrm{~min}$ for NearTIF), and $14 \mathrm{~min}$ when using the $10 \mathrm{~min} \mathrm{~W}$ phase solution. These forecasts may give more than half an hour before the tsunami hits the shore, which might be enough time to evacuate coastal communities. For the tFISH 20 min and 35 min solutions, the tsunami inundation forecasts could be ready for dissemination within 24 min and 
Table 1. $K$ and $\kappa$ for tFISH 35 min Solution at Every Site

\begin{tabular}{lccccc} 
& \multicolumn{2}{c}{ Numerical Forward Modeling } & & \multicolumn{2}{c}{ NearTIF } \\
\cline { 2 - 3 } \cline { 6 - 7 } Site & $\kappa$ & $\kappa$ & & $\kappa$ & $\kappa$ \\
\hline Miyako & 1.15 & 1.41 & & 1.37 & 1.60 \\
Yamada & 1.10 & 1.28 & & 1.75 & 1.64 \\
Otsuchi & 1.03 & 1.24 & & 1.37 & 1.38 \\
Kamaishi & 0.96 & 1.42 & & 1.11 & 1.58 \\
Yoshihama & 1.00 & 1.23 & & 1.28 & 1.24 \\
Sanriku & 1.12 & 1.31 & & 1.30 & 1.43 \\
Ofunato & 0.99 & 1.27 & & 1.11 & 1.33 \\
Rikuzentakata & 0.97 & 1.17 & & 1.06 & 1.19 \\
Kesennuma & 0.99 & 1.53 & & 1.40 & 1.50 \\
Motoyoshi & 1.23 & 1.39 & & 1.54 & 1.44 \\
Minamisanriku & 1.08 & 1.32 & & 1.24 & 1.30 \\
Oppa & 1.00 & 1.99 & & 1.09 & 2.04 \\
Onagawa & 1.18 & 1.68 & & 1.36 & 1.67 \\
Ishinomaki & 0.73 & 2.10 & & 0.89 & 2.22 \\
Sendai & 0.64 & 1.71 & & 0.70 & 1.72 \\
\hline
\end{tabular}

39 min, respectively, after the earthquake occurred (Table 3). The actual tsunami arrival time ranged from 60 to $80 \mathrm{~min}$ for the Sendai Plain, while other places in Miyagi and Iwate prefectures experienced arrival times from 25 to 55 min after the earthquake [Muhari et al., 2012].

The tsunami waveforms at the virtual observation points can be synthesized simultaneously with the initial sea surface height determination by the tFISH algorithm within 1 min after tsunami waveform data are obtained. This increases the forecasting speed because simulating tsunami waveforms becomes unnecessary. As mentioned above, NearTIF requires $1 \mathrm{~min}$ to find the site-specific best scenarios. When tFISH and NearTIF are combined, it could take 2 min to obtain tsunami inundation forecasts for near-field sites after the tsunami waveform data are obtained. In this study we show the length of time required to perform NearTIF using a laptop computer; the required time would be much less on a dedicated powerful computer.

\section{Discussion}

7.1. Uncertainty

A site-specific best scenario gives the smallest root-mean-square misfit (RMSE) between tsunami waveforms simulated in real time and the precomputed tsunami waveforms. To calculate the uncertainty of a tsunami inundation forecast from that scenario, we used the best scenario and also nine other scenarios with the smallest RMSE. The difference between the forecasted tsunami height and tsunami height from each other scenario at each inundated point is calculated. Then the standard deviation of the differences from nine scenarios is calculated to get the forecast uncertainty at each inundated point. The mean calculated uncertainty for the tsunami inundation forecast from the tFISH 35 min solution in Rikuzentakata is $\pm 1.44 \mathrm{~m}$ (Figure 13b). This is relatively small (about $12 \%$ of uncertainty) compared to the forecasted tsunami heights that are mostly larger than $10 \mathrm{~m}$ with an average of $12.39 \mathrm{~m}$ (Figure 13a). At a steep area, a $1-3 \mathrm{~m}$ higher tsunami will not significantly change the limit of inundation; however, if it is at a very flat area such as a flood plain then the limit of inundation can be significantly different. The quantiles for given probabilities of $0.85,0.95$, and 0.99 in the uncertainty distribution, respectively, are $\pm 2.01, \pm 2.17$, and $\pm 2.34 \mathrm{~m}$. The following equations were used to calculate uncertainty at each point.

$$
\begin{gathered}
\sigma_{x, y}=\sqrt{\frac{1}{N} \sum_{i=1}^{N}\left(\Delta \eta_{i(x, y)}-\mu_{(x, y)}\right)^{2}} ; \\
\mu_{(x, y)}=\frac{1}{N} \sum_{i=1}^{N} \Delta \eta_{i(x, y)} ; \Delta \eta_{i(x, y)}=\eta_{f(x, y)}-\eta_{i(x, y)}
\end{gathered}
$$

Table 2. Run-times Required to Obtain Tsunami Inundation Forecasts by Numerical Forward Modeling (NFM) and NearField Tsunami Inundation Forecasting (NearTIF)

\begin{tabular}{lccccc}
\multirow{N}{*}{$\begin{array}{l}\text { Number of } \\
\text { Sites }\end{array}$} & $\begin{array}{c}\text { Numerical Forward } \\
\text { Modeling }\end{array}$ & \multicolumn{3}{c}{ NearTIF } & \multirow{2}{*}{$\begin{array}{c}\text { Speed of NearTIF } \\
\text { Relative to NFM }\end{array}$} \\
\cline { 3 - 4 } 1 site & $2 \mathrm{~h}$ & Tsunami Model & Search Engine & Total & \\
15 sites & $40 \mathrm{~h}$ & $2 \mathrm{~min}$ & $3 \mathrm{~s}$ & $2 \mathrm{~min}$ & 60 times faster \\
\hline
\end{tabular}


Table 3. Capability of Each Earthquake or Tsunami Source Inversion Method and the Required Time to Obtain a Tsunami Inundation Forecast

\begin{tabular}{|c|c|c|c|c|c|}
\hline \multirow{3}{*}{$\begin{array}{l}\text { Method } \\
\text { RAPiD (Real-time automatic } \\
\text { detection method for } \\
\text { permanent displacement) }\end{array}$} & \multirow{3}{*}{$\begin{array}{c}\text { Capability } \\
\begin{array}{c}\text { Estimate fault model from } \\
\text { GPS data }\end{array}\end{array}$} & \multirow{3}{*}{$\frac{\text { Input }}{\text { GPS time series data }}$} & \multicolumn{3}{|c|}{ Required Time } \\
\hline & & & \multicolumn{2}{|c|}{$\begin{array}{l}\text { To Obtain Source } \\
\text { Model/Parameters }\end{array}$} & \multirow{2}{*}{$\begin{array}{c}\begin{array}{c}\text { To Obtain Tsunami } \\
\text { Inundation Forecast }\end{array} \\
8 \mathrm{~min}\end{array}$} \\
\hline & & & Using 5 min data & $5 \mathrm{~min}$ & \\
\hline W phase inversion & $\begin{array}{c}\text { Estimate centroid moment tensor } \\
\text { solution from W phase data }\end{array}$ & W phase data & $\begin{array}{l}\text { Using } 5 \mathrm{~min} \text { data } \\
\text { Using } 10 \mathrm{~min} \text { data }\end{array}$ & $\begin{array}{l}6 \mathrm{~min} \\
11 \mathrm{~min}\end{array}$ & $\begin{array}{l}9 \min \\
14 \min \end{array}$ \\
\hline $\begin{array}{l}\text { tFISH (The tsunami forecasting } \\
\text { based on inversion for initial } \\
\text { sea surface height) }\end{array}$ & $\begin{array}{c}\text { Estimate sea surface deformation } \\
\text { from tsunami waveform data }\end{array}$ & Tsunami waveform data & $\begin{array}{l}\text { Using } 20 \mathrm{~min} \text { data } \\
\text { Using } 35 \mathrm{~min} \text { data }\end{array}$ & $\begin{array}{l}21 \mathrm{~min} \\
36 \mathrm{~min}\end{array}$ & $\begin{array}{l}24 \min \\
39 \min \end{array}$ \\
\hline
\end{tabular}

where $\sigma_{x, y}$ is uncertainty at point $x$ and $y, N$ is the number of scenarios, in this case $N=9, \Delta \eta_{i(x, y)}$ is the difference between forecasted tsunami height and tsunami height from another scenario, $\mu_{(x, y)}$ is the average of the differences, $\eta_{f(x, y)}$ is forecasted tsunami height, and $\eta_{i(x, y)}$ is tsunami height from another scenario. To calculate the uncertainty of a tsunami inundation forecast, the following equation was used.

$$
\sigma=\frac{1}{M} \sum_{z=1}^{M} \sigma_{X_{z}, y_{z}}
$$

where $\sigma$ is the uncertainty of the tsunami inundation forecast, $M$ is the number of inundated points from the best scenario, and $\sigma_{x_{z}, y_{z}}$ is the uncertainty at inundated point $x_{z}$ and $y_{z}$.

\subsection{Tsunami Database Expansion}

For the case of the RAPiD solution, the tsunami inundation produced by NearTIF better resembles the observation compared to the tsunami inundation from numerical forward modeling. However, this is problematic because a NearTIF result should closely resemble the tsunami inundation from numerical forward modeling. More hypothetical earthquake scenarios can be added to expand the tsunami database. This expansion can increase the capability of NearTIF algorithm to give a more valid result. For the expansion, slip amount of every scenario is multiplied by a factor of 0.5 , while other parameters of the fault model are maintained. We searched a new best scenario by using the expanded tsunami waveform
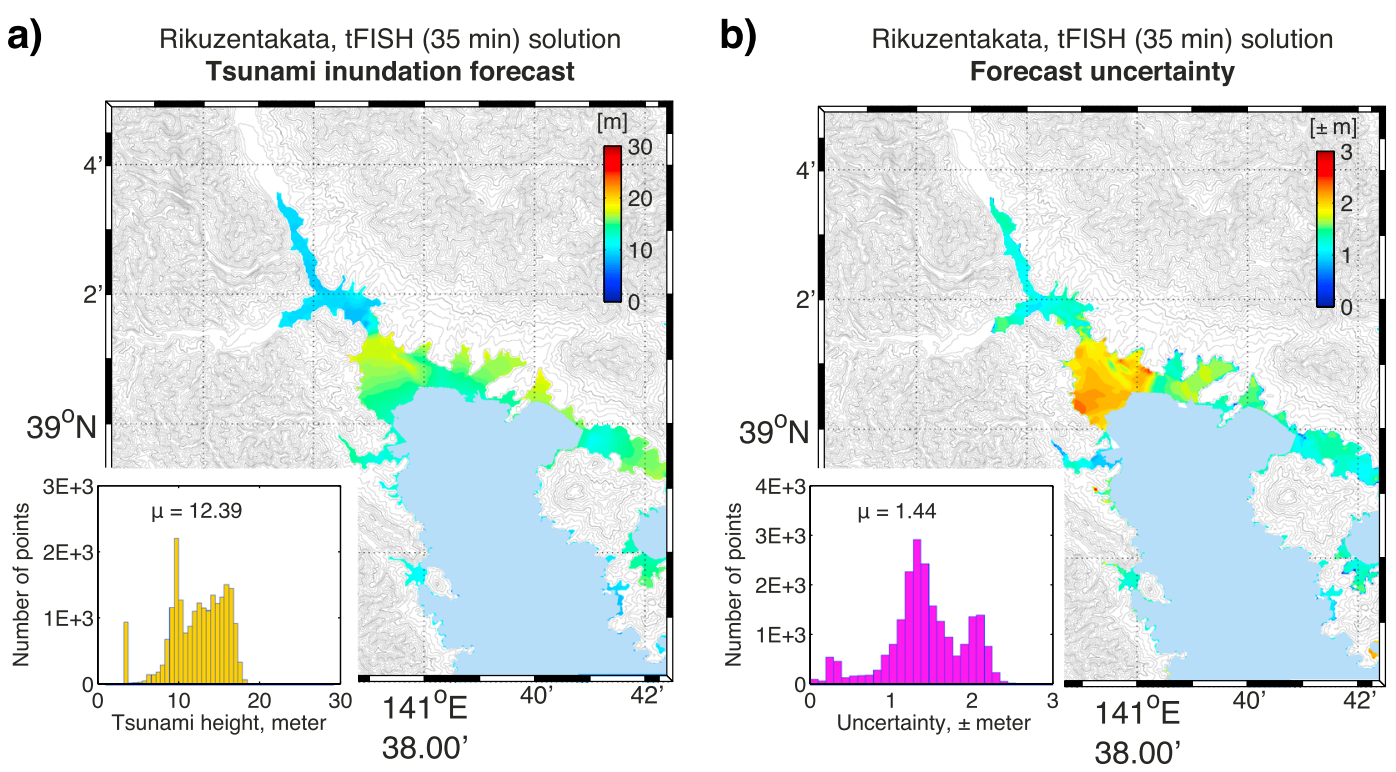

Figure 13. (a) Tsunami inundation forecast and (b) its uncertainty for Rikuzentakata from the tFISH 35 min solution. The color scale for the tsunami inundation forecast is 10 times larger than the color scale for the forecast uncertainty. 
a)

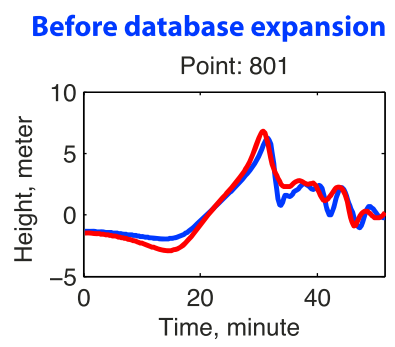

After database expansion Point: 801

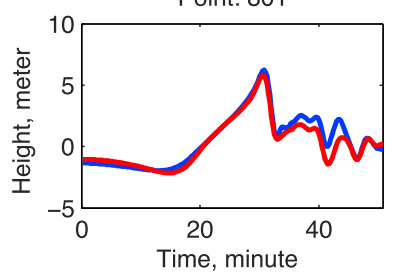

Numerical forward model Best scenario b)

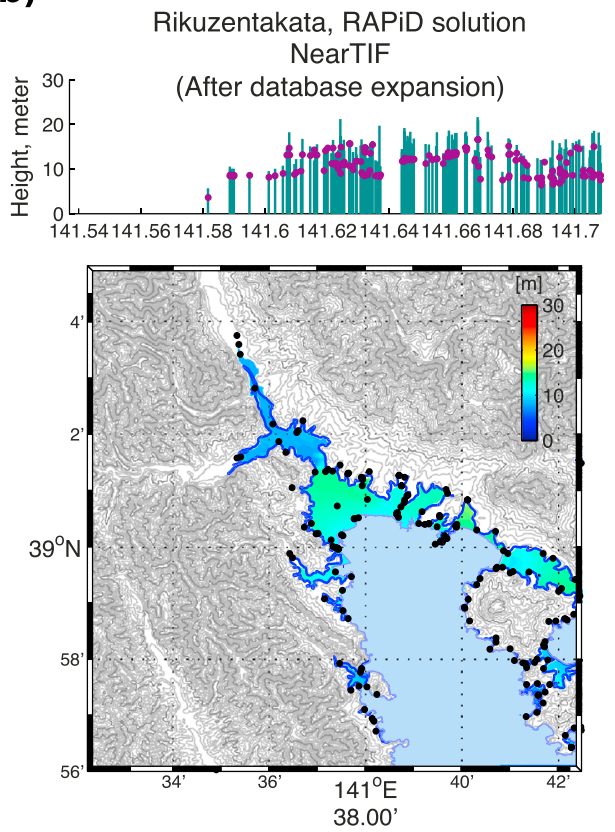

Tsunami Height $\mathrm{K}=1.28$ $\kappa=1.21$

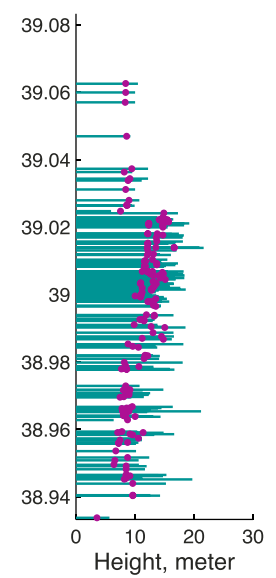

Figure 14. (a) Comparison of tsunami waveforms from numerical forward modeling and the best fit scenario for before and after the expansion of precomputed tsunami waveform database. (b) Forecasted tsunami inundation in Rikuzentakata from RAPiD solution after the expansion of precomputed tsunami database.

database. The new best scenario gives an RMSE of 0.653 , which is smaller than the RMSE $=0.744$ of the original result (Figure 14a). As expected, the tsunami inundation from the new best scenario (Figure 14b) has a very similar accuracy to tsunami inundation from numerical forward modeling (Figure 8a).

By adding more hypothetical scenarios, the precomputed tsunami waveform and tsunami inundation database can be expanded. This increases the possibility of obtaining the best scenario with smaller misfit of tsunami waveforms and therefore a more valid tsunami inundation forecast. The only downside of having a larger database is that it takes longer to search for the best scenario.

\subsection{Other Fault Mechanisms of Tsunamigenic Earthquakes}

In this study, we used a thrust mechanism for the hypothetical earthquake scenarios because many tsunamigenic earthquakes including the 2011 Tohoku earthquake are interplate thrust earthquakes. Tsunamigenic earthquakes may also have normal fault or reverse fault mechanism in the outer rise. There is a special class of earthquakes known as tsunami earthquake that generates tsunami much larger than expected from its surface wave magnitude [Kanamori, 1972]. While tsunami earthquakes may have thrust mechanisms like typical earthquakes, their distinctive larger slips near the trench required NearTIF to have expanded database with other hypothetical earthquake scenarios that resemble the characteristics of tsunami earthquake.

Several outer-rise earthquakes with normal fault mechanism that generated large tsunami occurred in March 1933 in Sanriku, Japan (Mw 8.4) [Kanamori, 1971; Abe, 1978], August 1977 in Sumba (Mw 8.2) [Gusman et al., 2009], January 2007 at Kuril Islands (Mw 8.0) [Tanioka et al., 2008], and September 2009 at Samoa Islands (Mw 8.1) [Lay et al., 2010; Tonini et al., 2011]. An outer-rise earthquake with reverse fault mechanism occurred on 31 August 2012 in the Philippines (Mw 7.6) (USGS) generated a small tsunami. Tsunami earthquakes have occurred in 1896 in Sanriku [Tanioka and Satake, 1996], 1994 in East Java [Maramai and Tinti, 1997; Tsuji et al., 1995], 2006 in West Java [Fritz et al., 2007; Bilek and Engdahl, 2007], and 2010 in Mentawai [Newman et al., 2011; Satake et al., 2013b], for example. Hypothetical earthquake scenarios with tsunami earthquake, normal fault, and reverse fault mechanisms should be included in the future improvement of NearTIF. 


\subsection{Improvement to Tsunami Source Model}

The tsunami source model of tFISH 35 min gives the most accurate tsunami inundations compared with the other solutions. However, the time required to obtain this source model ( $35 \mathrm{~min}$ for data and $1 \mathrm{~min}$ for inversion) is much longer than those required to obtain the $\mathrm{W}$ phase (5-10 min for data and $1 \mathrm{~min}$ for inversion) or RAPiD ( $5 \mathrm{~min}$ ) solutions. A minimum requirement for valid tsunami source estimation is to use the half period (generally 10-15 min for an earthquake-generated tsunami) of the first distinct wave from one tsunami pressure gauge [Wei et al., 2013]. Deployment of more tsunami gauges closer to the source area will enable faster detection of tsunami generation and propagation within minutes of the earthquake origin time, and provide an accurate estimate of the source of the tsunami in less time [Wei et al., 2013]. A dense network of tsunami pressure gauges is being installed in the Japan Trench subduction zone [Monastersky, 2012]. When the network is available, tsunami waveforms from those instruments could be used to estimate the tsunami source for tsunami early warning.

\subsection{Improvement to Tsunami Inundation Numerical Model}

There are significant discrepancies between tsunami heights simulated from the tFISH 35 min solution and the observation at V-shape valleys along the Sanriku Coast (Figures S1-S15). Three-dimensional tsunami simulation by Kim et al. [2013] can reproduce extreme runups of the 2011 Tohoku tsunami along a steep slope in Kaborinai in the northern part of Sanriku Coast. Their study shows that water flow that climbed the steep slope possessed a strong vertical velocity component; this vertical velocity component is assumed to be zero in our study.

The simulated tsunami inundation in Sendai Plain from the tFISH 35 min solution has the lowest accuracy (Figure 6a) compared to those for other sites. At the time of the 2011 Tohoku tsunami, the Sendai Plain was covered by a wide area of farmland at the back of a then 200 to $400 \mathrm{~m}$ wide coastal forest. Appropriate selection of Manning's roughness based on the land cover can improve the accuracy of tsunami inundation simulation as shown by Maclnnes et al. [2013]. The use of three-dimensional tsunami simulation and including the effect of land cover to the simulation may improve the accuracy of simulated tsunami inundation.

\section{Conclusions}

Tsunami inundation forecast on high-resolution topography can help to make a decision for evacuation during a tsunami event. Tsunami inundation can be simulated accurately by solving the nonlinear shallow water wave equations. However, high-resolution tsunami simulation is numerically expensive. To resolve this challenge, we develop a new methodology for Near-field Tsunami Inundation Forecasting (NearTIF) that is equipped with a database of precomputed tsunami waveforms and precomputed tsunami inundation.

Once information about the tsunami source is obtained from geodetic, seismological, or tsunami waveform data, tsunami waveforms at nearshore points can be simulated in real time. One of the scenarios in the database is selected as the site-specific best scenario by minimizing the root-mean-square misfit between the simulated tsunami waveforms and those in the database. Then the corresponding precomputed tsunami inundation of the best scenario is selected as the tsunami inundation forecast.

In this study we applied the method in a retrospective forecast test for the 2011 Tohoku tsunami. We simulated tsunami inundation in 15 sites along the Sanriku Coast from the Sendai Plain to Miyako City. The tsunami inundation forecasted by the NearTIF algorithm is quantitatively similar to the results from numerical forward simulations and thus is a fast alternative to the slower numerical simulation.

The accuracy of tsunami inundation forecast depends on the accuracy of the given tsunami source model. We used one fault model based on GPS inversion using 5 min data, two fault models based on W phase inversion using $5 \mathrm{~min}$ and $10 \mathrm{~min}$ data, and two source models from tsunami waveform inversion using $20 \mathrm{~min}$ and $35 \mathrm{~min}$ data. The tsunami source model that used $35 \mathrm{~min}$ of tsunami waveform data required more time to be obtained but gave the most accurate tsunami inundation forecast compared to the results from other solutions. Tsunami inundation forecasts results from all of the three fault models and the 35 min tsunami source model are reliable for tsunami early warning purposes. Updating tsunami warnings in real time can potentially contribute to saving lives in the minutes of hours following a large earthquake and tsunami. 
In general, the forecasted tsunami inundations from the tFISH 35 min solution produced by numerical forward model can explain well the observations. However, some discrepancies remain in some sites (e.g., the Sendai Plain or at V-shaped valleys along the Sanriku Coast). The discrepancies can be attributed to at least two factors, which are (1) the single assumed value of Manning's roughness that may be too simple to model the effect of land cover in some sites, and (2) the limitation of two-dimensional numerical forward model that assumed the vertical velocity component as zero.

The tsunami inundation produced by the NearTIF algorithm should resemble that from numerical forward modeling as closely as possible. Our database expansion test for the RAPiD solution in Rikuzentakata shows that the reliability of the NearTIF algorithm can be improved by increasing the number of scenarios in the database. We conclude that a fully operational tsunami inundation forecasting system based on the NearTIF algorithm should contain a huge number of scenarios with variable earthquake source parameters (i.e., strike, dip, rake, slip amount, and depth) or tsunami source models.

\section{Acknowledgments}

We thank Robert Nowack, an associate editor, Stefano Lorito, and an anonymous reviewer for their constructive comments. We thank Hamzah Latief (Bandung Institute of Technology) for discussion on tsunami inundation modeling. The bathymetric data set used for tsunami simulation is based on the General Bathymetric Chart of the Oceans (GEBCO) 30 arc sec grid resolution, Japan Hydrographic Association's M7005 bathymetric contour data, and digital elevation model (topographic data) of Geospatial Information Authority of Japan (GSI) with 50 m of grid resolution.

\section{References}

Abe, K. (1978), A dislocation model of the 1933 Sanriku earthquake consistent with the tsunami waves, J. Phys. Earth, 29, 381-396. Aida, I. (1978), Reliability of a tsunami source model derived from fault parameters, J. Phys. Earth, 26, 57-73.

Benavente, R., and P. R. Cummins (2013), Simple and reliable finite fault solutions for large earthquakes using the W-phase: The Maule $(M w=8.8)$ and Tohoku ( $M w=9.0)$ earthquakes, Geophys. Res. Lett., 40, 3591-3595, doi:10.1002/grl.50648.

Bilek, S. L., and E. R. Engdahl (2007), Rupture characterization and aftershock relocations for the 1994 and 2006 tsunami earthquakes in the Java subduction zone, Geophys. Res. Lett., 34, L20311, doi:10.1029/2007GL031357.

Blaser, L., F. Krüger, M. Ohrnberger, and F. Scherbaum (2010), Scaling relations of earthquake source parameter estimates with special focus on subduction environment, Bull. Seismol. Soc. Am., 100(6), 2914-2926, doi:10.1785/0120100111.

Duputel, Z., L. Rivera, H. Kanamori, G. P. Hayes, B. Hirsorn, and S. Weinstei (2011), Real-time W phase inversion during the 2011 off the Pacific coast of Tohoku earthquake, Earth Planets Space, 63(7), 535-539, doi:10.5047/eps.2011.05.032.

Fritz, H. M., et al. (2007), Extreme runup from the 17 July 2006 Java tsunami, Geophys. Res. Lett., 34, L12602, doi:10.1029/ 2007 GL029404.

Fujii, Y., K. Satake, S. Sakai, M. Shinohara, and T. Kanazawa (2011), Tsunami source of the 2011 off the Pacific coast of Tohoku, Japan earthquake, Earth Planets Space, 63(7), 815-820.

Gica, E., M. C. Spillane, V. V. Titov, C. D. Chamberlin, and J. C. Newman (2008), Development of the forecast propagation database for NOAA's Short-Term Inundation Forecast for Tsunamis (SIFT), Tech. Memo. OAR PMEL-139, 89 pp., Gov. Print. Off., Seattle, Wash.

Goto, C., Y. Ogawa, N. Shuto, and F. Imamura (1997), Numerical Method of Tsunami Simulation With the Leap-Frog Scheme, IUGG/IOC TIME Project, IOC Manual and Guides, vol. 35, pp. 1-126, UNESCO, Paris, France.

Gusman, A. R., and Y. Tanioka (2013), W phase inversion and tsunami inundation modeling for tsunami early warning: Case study for the 2011 Tohoku event, Pure Appl. Geophys., doi:10.1007/s00024-013-0680-z.

Gusman, A. R., Y. Tanioka, H. Matsumoto, and S.-I. Iwasaki (2009), Analysis of the tsunami generated by the great 1977 Sumba earthquake that occurred in Indonesia, Bull. Seismol. Soc. Am., 99, 2169-2179, doi:10.1785/0120080324.

Gusman, A. R., Y. Tanioka, S. Sakai, and H. Tsushima (2012), Source model of the great 2011 Tohoku earthquake estimated from tsunami waveforms and crustal deformation data, Earth Planet. Sci. Lett., 341-344, 234-242, doi:10.1016/j.epsl.2012.06.006.

Hanks, T. C., and W. H. Bakun (2002), A bilinear source-scaling model for M-log A observations of continental earthquakes, Bull. Seismol. Soc. Am., 92(5), 1841-1846.

Hayes, G. P., D. J. Wald, and R. L. Johnson (2012), Slab1.0: A three-dimensional model of global subduction zone geometries, J. Geophys. Res., 117, B01302, doi:10.1029/2011JB008524.

Ide, S., A. Baltay, and G. C. Beroza (2011), Shallow dynamic overshoot and energetic deep rupture in the 2011 Mw 9.0 Tohoku-Oki earthquake, Science, 332(6036), 1426-1429, doi:10.1126/science.1207020.

Imamura, F. (1996), Review of tsunami simulation with a finite difference method, in Long-Wave Run-up Models, edited by H. Yeh, P. Liu, and C. Synolakis, pp. 231-241, World Scientific, Singapore.

Imamura, F. (2009), Tsunami modeling: Calculating inundation and hazard maps, in The Sea, Volume 15: Tsunamis, edited by E. N. Bernard and A. R. Robinson, chap. 10, pp. 321-332, Harvard Univ. Press, Cambridge, Mass.

Johnson, J. M. (1998), Heterogeneous coupling along Alaska-Aleutians as inferred from tsunami, seismic, and geodetic inversions, Adv. Geophys., $39,1-116$.

Kamigaichi, O. (2011), Tsunami forecasting and warning, in Extreme Environmental Events, Complexity in Forecasting and Early Warning, edited by R. A. Meyers, pp. 982-1007, Springer, New York, doi:10.1007/978-1-4419-7695-6_52.

Kanamori, H. (1971), Seismological evidence for a lithospheric normal faulting-The Sanriku earthquake of 1933, Phys. Earth Planet. Inter., 4, 289-300.

Kanamori, H. (1972), Mechanism of tsunami earthquakes, Phys. Earth Planet. Inter., 6, 346-359, doi:10.1016/0031-9201(72)90058-1.

Kanamori, H. (1993), W phase, Geophys. Res. Lett., 20(16), 1691-1694, doi:10.1029/93GL01883.

Kanamori, H., and L. Rivera (2008), Source inversion of W phase: Speeding up seismic tsunami warning, Geophys. J. Int., 175, 222-238, doi:10.1111/j.1365-246X.2008.03887.x.

Kim, D. C., K. O. Kim, E. Pelinovsky, I. Didenkulova, and B. H. Choi (2013), Three-dimensional tsunami runup simulation for the port of Koborinai on the Sanriku Coast of Japan, J. Coastal Res., 65, 266-271, doi:10.2112/SI65-046.1.

Koshimura, S., T. Oie, H. Yanagisawa, and F. Imamura (2009), Developing fragility function for tsunami damage estimation using numerical model and post-tsunami data from Banda Aceh, Indonesia, Coastal Eng. J., 51(3), 243-273.

Lay, T., C. J. Ammon, H. Kanamori, L. Rivera, K. D. Koper, and A. R. Hutko (2010), The 2009 Samoa-Tonga great earthquake triggered doublet, Nature, 466, 964-968, doi:10.1038/nature09214.

Lay, T., H. Kanamori, C. J. Ammon, K. D. Koper, A. R. Hutko, L. Ye, H. Yue, and T. M. Rushing (2012), Depth-varying rupture properties of subduction zone megathrust faults, J. Geophys. Res., 117, B04311, doi:10.1029/2011JB009133. 
MacInnes, B. T., A. R. Gusman, R. J. LeVeque, and Y. Tanioka (2013), Comparison of earthquake source models for the 2011 Tohoku event using tsunami simulations and near-field observations, Bull. Seismol. Soc. Am., 103, 1256-1274, doi:10.1785/0120120121.

Maramai, A., and S. Tinti (1997), Coastal effects and damage due to the 3rd June, 1994 Java tsunami, in Perspective on Tsunami Hazard Reduction, Observations, Theory and Planning, edited by G. T. Hebenstreit, pp. 1-20, Kluwer Acad., Dordrecht, Netherlands.

Masamura, K., K. Fujima, C. Goto, K. lida, and T. Shigemura (2000), Theoretical solution of long wave considering the structure of bottom boundary layer and examinations on wave decay due to sea bottom friction [in Japanese], J. Hydraul. Coastal Environ. Eng., JSCE, 663/II-53, 369-378.

Mofjeld, H. O., V. V. Titov, F. I. González, and J. C. Newman (2001), Tsunami scattering provinces in the Pacific Ocean, Geophys. Res. Lett., 28(2), 335-337, doi:10.1029/2000GL011710.

Monastersky, R. (2012), Tsunami forecasting: The next wave, Nature, 483, 144-146, doi:10.1038/483144a.

Mori, N., T. Takahashi, and The 2011 Tohoku Earthquake Tsunami Joint Survey Group (2012), Nationwide post event survey and analysis of the 2011 Tohoku earthquake tsunami, Coastal Eng. J., 54(1), 1250001, doi:10.1142/S0578563412500015.

Muhari, A., F. Imamura, A. Suppasri, and E. Mas (2012), Tsunami arrival time characteristics of the 2011 East Japan Tsunami obtained from eyewitness accounts, evidence and numerical simulation, J. Nat. Disaster Sci., 34(1), 91-104.

Nakamura, M. (2006), Source fault model of the 1771 Yaeyama tsunami, southern Ryukyu Islands, Japan, inferred from numerical simulation, Pure Appl. Geophys., 163, 41-54, doi:10.1007/s00024-005-0007-9.

Nakamura, M. (2009), Fault model of the 1771 Yaeyama earthquake along the Ryukyu Trench estimated from the devastating tsunami, Geophys. Res. Lett., 36, L19307, doi:10.1029/2009GL039730.

Newman, A. V., G. Hayes, Y. Wei, and J. Convers (2011), The 25 October 2010 Mentawai tsunami earthquake, from real-time discriminants, finite-fault rupture, and tsunami excitation, Geophys. Res. Lett., 38, L05302, doi:10.1029/2010GL046498.

Ohta, Y., et al. (2012), Quasi real-time fault model estimation for near-field tsunami forecasting based on RTK-GPS analysis: Application to the 2011 Tohoku-Oki earthquake (Mw 9.0), J. Geophys. Res., 117, B02311, doi:10.1029/2011JB008750.

Okada, Y. (1985), Surface deformation due to shear and tensile faults in a half-space, Bull. Seismol. Soc. Am., 75, 1135-1154.

Ozaki, T. (2011), Outline of the 2011 off the Pacific coast of Tohoku earthquake (Mw 9.0)-Tsunami warnings/advisories and observations, Earth Planets Space, 63(7), 827-830.

Ozawa, S., T. Nishimura, H. Suito, T. Kobayashi, M. Tobita, and T. Imakiire (2011), Coseismic and postseismic slip of the 2011 magnitude-9 Tohoku-Oki earthquake, Nature, 475, 373-376, doi:10.1038/nature10227.

Romano, F., A. Piatanesi, S. Lorito, N. D'Agostino, K. Hirata, S. Atzori, and M. Cocco (2012), Clues from joint inversion of tsunami and geodetic data of the 2011 Tohoku-Oki earthquake, Sci. Rep., 2, 385, doi:10.1038/srep00385.

Satake, K. (2007), Volcanic origin of the 1741 Oshima-Oshima tsunami in the Japan Sea, Earth Planets Space, 59, 381-390.

Satake, K., and Y. Tanioka (2003), The July 1998 Papua New Guinea earthquake: Mechanism and quantification of unusual tsunami generation, Pure Appl. Geophys., 160, 2087-2118, doi:10.1007/s00024-003-2421-1.

Satake, K., Y. Fujii, T. Harada, and Y. Namegaya (2013a), Time and space distribution of coseismic slip of the 2011 Tohoku earthquake as inferred from tsunami waveform data, Bull. Seismol. Soc. Am., 103, 1473-1492, doi:10.1785/0120120122.

Satake, K., Y. Nishimura, P. S. Putra, A. R. Gusman, H. Sunendar, Y. Fujii, Y. Tanioka, H. Latief, and E. Yulianto (2013b), Tsunami source of the 2010 Mentawai, Indonesia earthquake inferred from tsunami field survey and waveform modeling, Pure Appl. Geophys., doi:10.1007/ s00024-012-0536-y.

Shimozono, T., S. Sato, A. Okayasu, Y. Tajima, H. M. Fritz, H. Liu, and T. Takagawa (2012), Propagation and inundation characteristics of the 2011 Tohoku tsunami on the central Sanriku Coast, Coastal Eng. J., 54(1), 1250004, doi:10.1142/S0578563412500040.

Simons, M., et al. (2011), The 2011 magnitude 9.0 Tohoku-Oki earthquake: Mosaicking the mega-thrust from seconds to centuries, Science, 332(6036), 1421-1425, doi:10.1126/science.1206731.

Tang, L., V. V. Titov, Y. Wei, H. O. Mofjeld, M. Spillane, D. Arcas, E. N. Bernard, C. Chamberlin, E. Gica, and J. Newman (2008), Tsunami forecast analysis for the May 2006 Tonga tsunami, J. Geophys. Res., 113, C12015, doi:10.1029/2008JC004922.

Tang, L., V. V. Titov, and C. D. Chamberlin (2009), Development, testing, and applications of site-specific tsunami inundation models for real-time forecasting, J. Geophys. Res., 114, C12025, doi:10.1029/2009JC005476.

Tanioka, Y., and K. Satake (1996), Fault parameters of the 1896 Sanriku tsunami earthquake estimated from tsunami numerical modeling, Geophys. Res. Lett., 23(13), 1549-1552, doi:10.1029/96GL01479.

Tanioka, Y., Y. Hasegawa, and T. Kuwayama (2008), Tsunami waveform analyses of the 2006 underthrust and 2007 outer-rise Kurile earthquakes, Adv. Geosci., 14, 129-134.

Tatehata, H. (1997), The new tsunami warning system of the Japan Meteorological Agency, in Advances in Natural and Technological Hazards Research, Perspectives on Tsunami Hazard Reduction, vol. 9, edited by G. Hebenstreit, pp. 175-188, Kluwer Acad., Dordrecht, Netherlands.

Titov, V. V. (2009), Tsunami forecasting, in The Sea, Volume 15: Tsunamis, chap. 12, edited by E. N. Bernard and A. R. Robinson, pp. 371-400, Harvard Univ. Press, Cambridge, Mass.

Titov, V. V., F. I. Gonzá lez, E. N. Bernard, M. C. Eble, H. O. Mofjeld, J. C. Newman, and A. J. Venturato (2005), Real-time tsunami forecasting: Challenges and solutions, Nat. Hazards, 35(1), 41-58.

Tonini, R., A. Armigliato, and S. Tinti (2011), The 29 September 2009 Samoa Islands tsunami: Simulations based on the first focal mechanism solutions and implications on tsunami early warning strategies, Pure Appl. Geophys., 168, 1113-1123, doi:10.1007/ s00024-010-0221-y.

Tsuji, Y., F. Imamura, H. MAtsutomi, C. E. Synolakis, P. T. Nanang, S. Jumadi, S. S. Harada, K. A. Han, and B. Cook (1995), Field survey of the East Java earthquake and tsunami of June 3, 1994, Pure Appl. Geophys., 144(3-4), 839-854, doi:10.1007/BF00874397.

Tsushima, H., R. Hino, H. Fujimoto, Y. Tanioka, and F. Imamura (2009), Near-field tsunami forecasting from cabled ocean bottom pressure data, J. Geophys. Res., 114, B06309, doi:10.1029/2008JB005988.

Tsushima, H., K. Hirata, Y. Hayashi, Y. Tanioka, K. Kimura, S. Sakai, M. Shinohara, T. Kanazawa, R. Hino, and K. Maeda (2011), Near-field tsunami forecasting using offshore tsunami data from the 2011 off the Pacific coast of Tohoku earthquake, Earth Planets Space, 63(7), 821-826, doi:10.5047/eps.2011.06.052.

Wei, Y., C. Chamberlin, V. V. Titov, L. Tang, and E. N. Bernard (2013), Modeling of 2011 Japan tsunami-Lessons for near-field forecast, Pure Appl. Geophys., 170, 1309-1331, doi:10.1007/s00024-012-0519-z.

Wells, D. L., and K. J. Coppersmith (1994), New empirical relationships among magnitude, rupture length, rupture width, rupture area, and surface displacement, Bull. Seismol. Soc. Am., 84(4), 974-1002.

Yeh, H. (2009), Tsunami impacts on coastlines, in The Sea, Volume 15: Tsunamis, chap. 11, edited by E. N. Bernard and A. R. Robinson, pp. 333-369, Harvard Univ. Press, Cambridge, Mass. 
Yokota, Y., K. Koketsu, Y. Fujii, K. Satake, S. Sakai, M. Shinohara, and T. Kanazawa (2011), Joint inversion of strong motion, teleseismic, geodetic, and tsunami datasets for the rupture process of the 2011 Tohoku earthquake, Geophys. Res. Lett., 38, L00G21, doi:10.1029/ 2011 GL050098.

Yoshida, Y., H. Ueno, D. Muto, and S. Aoki (2011), Source process of the 2011 Off the Pacific Coast of Tohoku earthquake with the combination of teleseismic and strong motion data, Earth Planets Space, 63(7), 565-569.

Yue, H., and T. Lay (2013), Source rupture models for the Mw 9.02011 Tohoku earthquake from joint inversions of high-rate geodetic and seismic data, Bull. Seismol. Soc. Am., 103(2B), 1242-1255, doi:10.1785/0120120119. 